Dear Author,

Please, note that changes made to the HTML content will be added to the article before publication, but are not reflected in this PDF.

Note also that this file should not be used for submitting corrections. 


\title{
Q1 Are large submarine landslides temporally random or do uncertainties in available age constraints make it impossible to tell?
}

\author{
E. Pope ${ }^{\text {a,* }}$, P.J. Talling a, M. Urlaub ${ }^{\text {b }}$, J.E. Hunt ${ }^{\text {a }}$, M.A. Clare ${ }^{\text {a }}$, P. Challenor ${ }^{\text {c }}$ \\ a National Oceanography Centre, Southampton, European Way, Southampton SO14 3ZH, UK \\ b GEOMAR Helmholtz Centre for Ocean Research Kiel, Wischhofstr. 1-3, 24148 Kiel, Germany \\ c College of Engineering, Mathematics and Physical Sciences, Harrison Building, North Park Road, EX4 4QF, UK
}

\section{A R T I C L E I N F O}

\section{Article history:}

Received 15 April 2015

Received in revised form 18 July 2015

Accepted 24 July 2015

Available online $\mathrm{xxxx}$

\section{Keywords:}

Submarine landslides

Sea level

Timing

Tsunami

\begin{abstract}
A B S T R A C T
Large $\left(>\sim 1 \mathrm{~km}^{3}\right)$ submarine landslides can potentially generate very destructive tsunamis and damage expensive 18 sea floor infrastructure. It is therefore important to understand their frequency and triggers, and whether their 19 frequency is likely to change significantly due to future climatic and sea level change. It is expensive to both 20 collect seafloor samples and to date landslides accurately; therefore we need to know how many landslides 21 we need to date, and with what precision, to answer whether sea level is a statistically significant control. Previ- 22 ous non-statistical analyses have proposed that there is strong correlation between climate driven changes and 23 landslide frequency. In contrast, a recent statistical analysis by Urlaub et al. (2013) of a global compilation of 24 41 large $\left(>1 \mathrm{~km}^{3}\right)$ submarine landslide ages in the last 30 ka concluded that these ages have a temporally random 25 distribution. This would suggest that landslide frequency is not strongly controlled by a single non-random global 26 factor, such as eustatic sea level. However, there are considerable uncertainties surrounding the age of almost all 27 large landslides, as noted by Urlaub et al. (2013). This contribution answers a key question that Urlaub et al. 28 (2013) posed, but could not address - are large submarine landslides in this global record indeed temporally ran- 29 dom, or are the uncertainties in landslide ages simply too great to tell? We use simulated age distributions in 30 order to determine the significance of available age constraints from real submarine landslides. First, it is 31 shown that realistic average uncertainties in landslide ages of \pm 3 kyr may indeed result in a near-random distri- 32 bution of ages, even where there are non-random triggers such as sea level. Second, we show how combination of 33 non-random landslide ages from just 3 different settings, can easily produce an apparently random distribution if 34 the landslides from different settings are out of phase. Third, if landslide frequency was directly proportional to 35 sea level, we show that at least 10 to 53 landslides would need to be dated perfectly globally - to show this cor- 36 relation. We conclude that it is prudent to focus on well-dated landslides from one setting with similar triggers, 37 rather than having a poorly calibrated understanding of ages in multiple settings.
\end{abstract}

(c) 2015 Published by Elsevier B.V.

\section{Introduction}

Submarine landslides are one of the volumetrically most important mechanisms through which sediment is transported from the continental slope to the deep ocean (Hühnerbach and Masson, 2004; Masson et al., 2006; Korup, 2012; Talling et al., 2012; Urlaub et al., 2013, 2014). Landslide deposits have been mapped on many continental slopes as disparate as southeast Australia (Clarke et al., 2012) and the Grand Banks, Newfoundland (Piper et al., 1999). Submarine landslides can be far larger than any terrestrial landslide, and can involve the movement of hundreds or even several thousands of cubic kilometres of material (Hampton et al., 1996; Hühnerbach and Masson, 2004; Talling et al., 2007). Perhaps the most remarkable aspect of large submarine landslides is that they typically can occur on very low gradients

\footnotetext{
* Corresponding author.

E-mail address: ed_pope@hotmail.co.uk (E. Pope).
}

of just 1-2 ${ }^{\circ}$ (Hühnerbach and Masson, 2004; Talling et al., 2007; Urlaub 57 et al., 2012, 2014). Such low gradients are almost always stable on land. Q4 Once in motion, the submarine slide mass can entrain ambient seawater 59 and disaggregate to form longer runout sediment flows, known as tur- 60 bidity currents. These turbidity currents can themselves travel many 61 hundreds of kilometres (Weaver and Kuijpers, 1983), and reach speeds 62 of up to 20 m/s (Piper et al., 1999; Hsu et al., 2008).

Submarine landslides, debris flows and associated turbidity currents 64 may represent significant geohazards. Submarine landslides have the 65 potential to generate damaging tsunamis (Ruffman, 2001; Tappin 66 et al., 2001; Haflidason et al., 2005; Boe et al., 2007; Hornbach et al., 67 2007); whilst both landslides and turbidity currents can damage expen- 68 sive sea floor infrastructure, such as that associated with the hydrocar- 69 bon industry or seafloor telecommunications (Bruschi et al., 2006; 70 Carter et al., 2009; Parker et al., 2009, 2012). Some authors have argued Q5 that the occurrence of large submarine landslides can have significant 72 climatic impacts through the release of large amounts of methane into 73 
the water column and the atmosphere (Kennett et al., 2000; Maslin et al., 2004; Pecher et al., 2005; Vanneste et al., 2006; Beget and Addison, 2007; Paull et al., 2007). Understanding the frequency and triggers of large submarine landslides is therefore important.

\subsection{Triggering and preconditioning of submarine landslides}

A large number of triggers and preconditioning factors have been hypothesised as possible causes for large submarine landslides. Potential preconditioning factors and triggers include earthquakes, rapid sedimentation that leads to high excess pore pressure and conditions close to failure, and gas hydrate dissociation that reduces sediment strength (Hampton et al., 1996; Maslin et al., 1998; Stigall and Dugan, 2010; Goldfinger, 2011; Masson et al., 2011; Talling et al., 2014). However, not all large $\left(>7 \mathrm{M}_{\mathrm{w}}\right)$ earthquakes appear to generate major slides (Völker et al., 2011; Sumner et al., 2013), large submarine landslides occur in locations with slow sediment accumulation (Urlaub et al., 2012), and some landslide headwalls occur in water depths that are too deep for gas hydrate dissociation (Hühnerbach and Masson, 2004). In general, many of these hypotheses for landslide preconditioning and triggering are weakly tested, in part because we are yet to directly monitor large slides in action in sufficient detail (Talling et al., 2014).

\subsection{Submarine landslide frequency and sea level - previous work}

A series of previous studies explored the potential relationship between landslide frequency and sea level. The first set of studies used compilations of landslide ages, typically from widespread locations.

\subsubsection{Global databases of landslide ages}

The initial analyses did not include full uncertainties in landslide ages, or test the certainty of their conclusions through quantitative statistical methods. These studies suggest that increased landslide frequency occurred during specific periods in glacial cycles, corresponding to sea level low-stands, high-stands, or rapid rates of sea level change. Brothers et al. (2013) identify a causal relationship between sea level rise and landslide triggering. Paull et al. (1996) identify increased numbers of landslides during low-stands related to reduced overburden pressure of the water column on gas hydrate bearing sediments. Leynaud et al. (2009), Maslin et al. (1998, 2004), Lee (2009) and Lebreiro et al. (2009) recognised that different margins responded differently to sea level. For example, low latitude margins experienced more large submarine landslides during low-stands while high latitudes were more likely to see slope failures during rising sea levels or highstands.

Subsequent analysis has sought to evaluate these qualitative conclusions using statistical approaches. Urlaub et al. (2013) considered a collection of 68 large $\left(>\sim 1 \mathrm{~km}^{3}\right)$ submarine landslide ages from locations worldwide, which includes the last $120 \mathrm{ka}$ (Fig. 1). This is the largest number of landslide ages yet compiled. It included dates from landslide deposits themselves from open slope failures (but not volcanic island failures) where ages were obtained by radiocarbon AMS measurements or by applying a combination of several methods (e.g. biostratigraphy and oxygen isotopes). It also included large $\left(>\sim 1 \mathrm{~km}^{3}\right)$ turbidites inferred to be landslide-triggered. Such large volume turbidites are unlikely to be triggered by processes other than slope failure, as their volume far exceeds even the largest historical river flood (Talling et al., 2014). In general, such turbidites will tend to record faster moving landslides that disintegrate to produce turbidity currents. See Urlaub et al. (2013) for a fuller discussion on the consistent selection criteria.

The Urlaub et al. (2013) study took a subset of 41 events in the last 30 ka to analyse statistically from the compiled global database. This subset was chosen to avoid a strong bias due to undersampling of older events, caused by limits to core penetration below the sea floor; most sediment cores extended back to $30 \mathrm{ka}$, but few reached $120 \mathrm{ka}$.
The analysis by Urlaub et al. (2013) included the often considerable un- 135 certainties in landslide ages in this analysis (Fig. 1), unlike most previ- 136 ous studies that considered only the calibrated mean ages or most 137 probable ages (Ramsey, 1998). The greatest uncertainties in landslide 138 age typically result from where samples are taken for dating, above 139 and below the landslide or turbidite deposit, rather than the error bars 140 in the (typically AMS radiocarbon) dates themselves. This is discussed 141 more fully in Urlaub et al. (2013), and illustrated by our Fig. 2 . 142

Urlaub et al. (2013) analysed these 41 landslide ages. They first 143 divided their 30 ka study period into a series of equal time intervals, 144 termed bins (e.g. 0-5 kyr, 5-10 kyr, and 10-15 kyr). They then 145 counted the number of landslide ages that fell within each bin. This 146 allowed them to plot the number of bins with a single landslide 147 age, two landslide ages, three landslide ages, and so forth (Urlaub 148 et al., 2013; their Fig. 8a, b). A random number generator was then 149 used to produce a set of synthetic landslide ages, assuming landslide 150 occurrence was temporally random. The same procedure was 151 followed to count the number of synthetic landslide ages in each 152 bin, and the number of bins with one, two or more landslide ages. 153 It was found that there was no statistically significant difference be- 154 tween the frequency of bins with 1, 2, 3 or more landslide ages, both 155 real and synthetic landslide ages using the $\chi^{2}$ statistic (their Fig. 8c). 156 The duration of bins was varied between $1 \mathrm{kyr}$ and $5 \mathrm{kyr}$, as this af- 157 fects the frequency distribution of the landslide ages. Both the 'best 158 guess' landslide ages, and landslide ages acknowledging age uncer- 159 tainty were tested in this way. In each case, landslide ages were de- 160 scribed by the $\chi^{2}$ statistic as occurring randomly, such that they 161 approximated a Poisson distribution (Urlaub et al., 2013).

A second type of study used different types of data and statistical 164 methods to consider the recurrence intervals of landslides around the 165 margins of a single sedimentary basin (Hunt et al., 2013; Clare et al., 166 2014), as opposed to a global dataset of landslide ages. These studies 167 used large volume turbidites as a proxy for large landslides that disinte- 168 grate, which are presumably faster moving. Clare et al. (2014) consid- 169 ered large $\left(>0.1 \mathrm{~km}^{3}\right.$ in these cases) landslide turbidite recurrence 170 intervals in three disparate abyssal plain sequences of variable age, 171 whilst Hunt et al. (2013) considered landslide-turbidites in the Agadir 172 Basin offshore NW Africa. They compared the frequency distribution 173 of landslide turbidite recurrence intervals, with a Poisson frequency dis- 174 tribution. It was found that the frequency distribution of the landslide- 175 turbidite recurrence intervals did not differ significantly from the 176 (Poisson) distribution produced by a temporally random process. Both 177 of these studies therefore suggest that large landslides, which disinte- 178 grate to form long run-out turbidity currents, are temporally random, 179 or near random (Hunt et al., 2013; Clare et al., 2014).

\subsubsection{Discrete vs continuous data}

Q6

The Urlaub et al. (2013), Hunt et al. (2013) and Clare et al. (2014) 182 studies all concluded that the occurrence of submarine landslides 183 followed a Poisson distribution. A Poisson distribution implies a lack of 184 memory in the system which it is describing, such that the probability 185 of a new event occurring is independent of the time since the last. The 186 methodology used by the different studies is dependent on the type of 187 data. The global nature of the Urlaub et al. (2013) study and the uncer- 188 tainty regarding the duration of inter-event timing required the study to 189 use 'discrete' (count) data that was binned. The number of landslides 190 within a given time period was compared to the number that would 191 theoretically be produced by a random process. In contrast, the avail- 192 ability of landslide-turbidite recurrence intervals (inter-event time) 193 allowed Hunt et al. (2013) and Clare et al. (2014) to use 'continuous' 194 data. This study follows the approach of Urlaub et al. (2013) and there- 195 fore uses discrete data. 


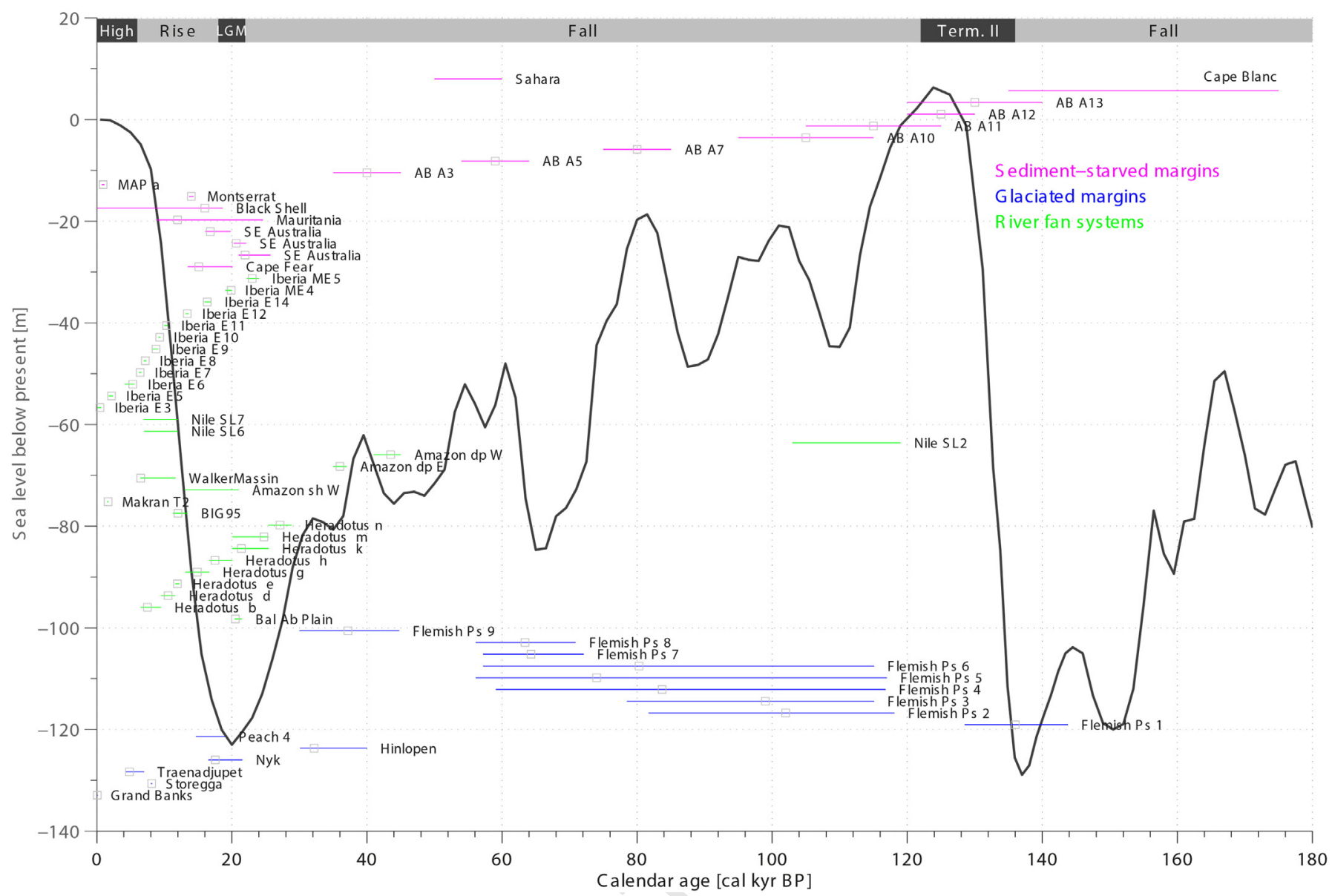

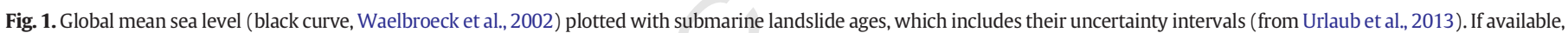

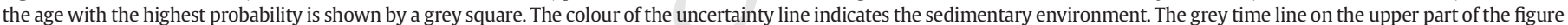
indicates the sea level pattern. (For interpretation of the references to colour in this figure legend, the reader is referred to the web version of this article.)
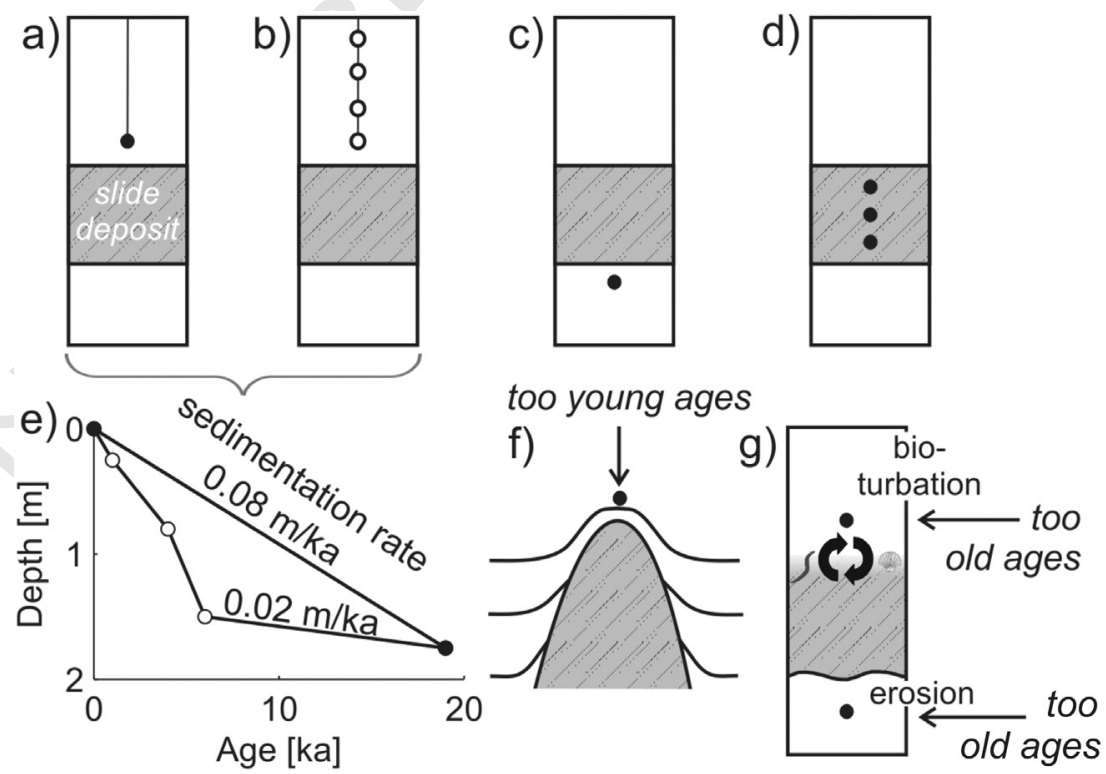

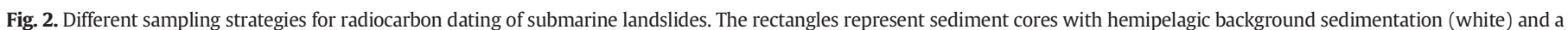

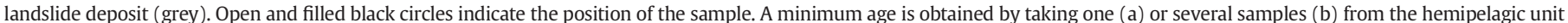

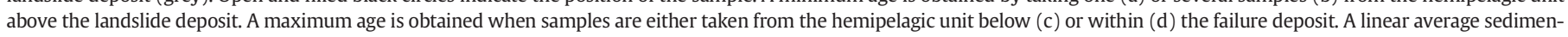

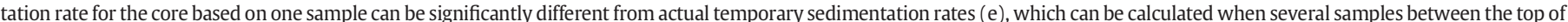

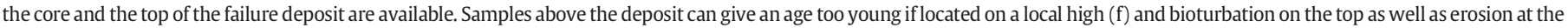
base of the failed deposit $(\mathrm{g})$ are possible sources of uncertainty to the estimated ages.

Fig. 1 from Urlaub et al., 2013. 


\subsection{Rationale for this study - why is it necessary, novel and valuable?}

This study answers the key outstanding questions that remain from the study of Urlaub et al. (2013), which concluded that large landslide ages were temporally random. They posed, but failed to answer the important question: is this because large submarine landslide ages are temporally random, or is it because the uncertainties in the ages are too large to tell? Here we provide a novel answer to that question. It is important to understand what this compilation of ages is telling us about landslide frequency, as each landslide age has been costly to acquire. For example, if landslide ages actually correlate perfectly with global sea level, is it likely that uncertainties in measuring their ages could easily produce an apparently random age distribution?

We also address two further key questions that have not previously been addressed. First, how easy is it to produce temporally random landslide ages simply from combining (non-random) landslide ages from multiple settings with different triggers and preconditioning factors? It is important to answer this question because this is indeed the situation for most global datasets of landslide ages, which combine dates from different settings, including that presented by Urlaub et al. (2013). Second, how many submarine landslides do we need to date, and with what precision, in order to test whether landslide frequency is controlled strongly by global sea level? This is important because it is costly to sample and date submarine landslides. We need to know what the most effective future strategy will be for determining whether landslides and sea level are linked.

\subsubsection{Why use simulated landslide ages?}

Our aim is to understand the significance of the available dates, with their uncertainties, from real large submarine landslides (such as compiled by Urlaub et al., 2013). However, to answer the three key science questions outlined above we first consider series of simulated landslide ages. We do not consider landslide ages from the original Urlaub et al., 2013 database. Our approach allows us to determine whether simulated landslide ages, which are perfectly known and lack any uncertainties, can form temporally random patterns once reasonable age uncertainties are added. Such an approach cannot be taken with real landslide ages, whose ages all have significant uncertainties. Similarly, the simulated ages allow us to investigate the ease with which perfectly known landslide ages from different settings (with variable triggers and preconditioning factors) can be combined to form apparently temporally random landslide ages. Finally, these simulated landslide ages allow us to test how many landslide ages are needed to identify a strong sea level control. It is impossible to do this using real landslide ages that all have different error bars, and for which we do not know there is a perfect association with sea level. So these synthetic landslide ages allow us to fix key parameters (e.g. error bars), to answer key questions about the real field datasets. An additional advantage of such simulated ages is that potential biases are avoided, such as the ages mostly coming from the northeast Atlantic as is the case for Urlaub et al. (2013).

\section{Methods}

This section first outlines the statistical method used to test for randomness in landslide ages (Section 2.1). It then describes how simulated (artificial) catalogues of landslide ages were created that are nonrandom, and have perfectly known ages (Section 2.2). Sections 2.2.1 and 2.2.2 outline how realistic uncertainties (error bars) were added to these simulated ages and how changes to the 1 kyr bins were investigated with regard to how event frequency is measured. Section 2.3 describes how simulated landslide ages from multiple settings are combined. Finally, Section 2.4 outlines the methodology used to test how many landslides are needed to identify a strong sea level control whose rationale for choosing rather than other variables is detailed in Section 2.5 .
To test for a temporally random distribution, we use the $\chi^{2}$ method- 259 ology outlined by Urlaub et al. (2013). The $\chi^{2}$ test assesses the goodness 260 of fit of a dataset to a temporally random distribution by analysing 261 whether there are statistically significant peaks, clusters or trends with- 262 in the dataset (Swan and Sandilands, 1995). As the $\chi^{2}$ test is testing a 263 temporal process, the data are split into time intervals of certain lengths 264 known as bins. The number of bins containing a certain number of land- 265 slides is counted. These are then compared to the number of bins with 266 an expected number of events according to a Poisson model generated 267 from the same number of events and bins. The distribution of events 268 is considered random if the $\chi^{2}$ value is smaller than the $\chi^{2}$ critical 269 value. The $\chi^{2}$ critical value is obtained from a look-up table depending 270 on the number of classes observed (see Swan and Sandilands (1995) 271 for further details). The critical values at the 95\% confidence level can 272 be seen in Table 1 .

In addition to the $\chi^{2}$ test set out in (Urlaub et al., 2013) we also use 274 the likelihood ratio $\chi^{2}$ test (Kendall et al., 1999). The likelihood ratio 275 $\chi^{2}$ test is defined as:

$G^{2}=2 \sum\left[O_{j} \log \frac{O_{j}}{E_{j}}\right]$

where $O_{j}$ is the number of bins observed with a given number of events 278 and $E_{j}$ is the number of bins expected with a given number of events (Kendall et al., 1999). The likelihood ratio test provides a means to ana- 279 lyse the likelihood of the landslide ages being random or non-random. If 280 the likelihood ratio exceeds a critical value then we have reason to reject 281 the distribution prescribed by the $\chi^{2}$ statistic. The critical value is obtain- 282 ed from the $\chi^{2}$ look-up table according to the number of classes 283 observed. Using the likelihood ratio in addition to the $\chi^{2}$ statistic 284 provides a more rigorous analysis.

\subsection{Creating simulated non-random landslides with perfectly known ages 286}

This study initially uses a set of artificially generated landslide ages 287 that are known perfectly, without any uncertainty, for reasons set out 288 in Section 1.3.1. Four types of non-random landslide age patterns 289 were investigated. Our aim was to understand how many of these per- 290 fectly known landslide ages we would need to measure to show if they 291 are random or non-random. Fig. 3 provides a visual explanation of each 292

\begin{tabular}{|c|c|c|}
\hline $\begin{array}{l}\text { Table } \\
\chi^{2} \text { crit }\end{array}$ & nce inter- & $\begin{array}{l}\mathrm{t} 1.1 \\
\mathrm{t} 1.2\end{array}$ \\
\hline val. A & cording to & $\mathrm{t} 1.3$ \\
\hline the $n$ & ipared, i.e. & $\mathrm{t} 1.4$ \\
\hline if thre & d such that & $\mathrm{t} 1.5$ \\
\hline there & landslides & $\mathrm{t} 1.6$ \\
\hline then & ees of free- & $\mathrm{t} 1.7$ \\
\hline dom & re are four & $\mathrm{t} 1.8$ \\
\hline classe & $t$ there are & $\mathrm{t} 1.9$ \\
\hline bins $\mathrm{v}$ & s then the & $\mathrm{t} 1.10$ \\
\hline critica & sen and so & $\mathrm{t} 1.11$ \\
\hline on. $\mathrm{W}$ & le exceeds & $\mathrm{t} 1.12$ \\
\hline the at & e distribu- & $\mathrm{t} 1.13$ \\
\hline tion 0 & dom. & $\mathrm{t} 1.14$ \\
\hline $\mathrm{v}$ & $95 \%$ & $\mathrm{t} 1.15$ \\
\hline 1 & 3.841 & $\mathrm{t} 1.16$ \\
\hline 2 & 5.991 & $\mathrm{t} 1.17$ \\
\hline 3 & 7.815 & $\mathrm{t} 1.18$ \\
\hline 4 & 9.488 & $\mathrm{t} 1.19$ \\
\hline 5 & 11.07 & $\mathrm{t} 1.20$ \\
\hline 6 & 12.592 & $\mathrm{t} 1.21$ \\
\hline 7 & 14.067 & $\mathrm{t} 1.22$ \\
\hline 8 & 15.507 & $\mathrm{t} 1.23$ \\
\hline 9 & 16.919 & $\mathrm{t} 1.24$ \\
\hline 10 & 18.307 & $\mathrm{t} 1.25$ \\
\hline
\end{tabular}




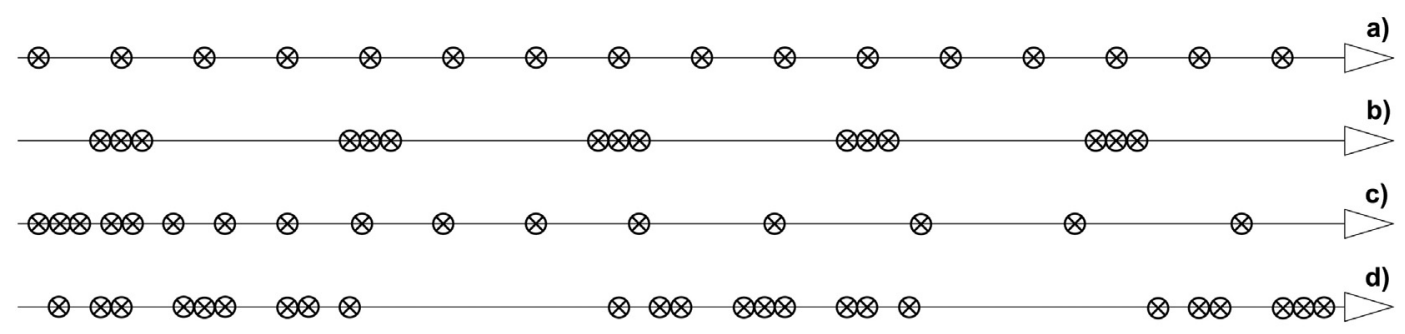

Time (t)

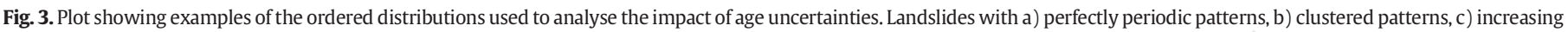
inter-event time patterns, d) patterned patterns.

Swan and Sandilands, 1995.

type of non-random age distribution. These four types of landslides ages are perfectly periodic, clustered, with linearly increasing inter-event times, or patterned in time (Fig. 3; Swan and Sandilands, 1995). Examples of functions used to generate perfectly periodic (Eq. (3)), clustered (Eq. (4)) and linearly increasing inter-event times (Eq. (5)) are shown below. Events are considered to occur when the value of $\mathrm{f}(\mathrm{x})$ is equal to 1 .

$f(x)=\sin (x)$

$f(x)=\sin (x)+\frac{1}{2} \sin x+0.1$

$f(x)=\sin \left(x^{x}\right)$

Patterned landslide ages were produced by using more than one of these generating functions. These patterned events were manipulated to change their average event frequency (Fig. 3). The number of events within an individual simulated catalogue of landslide ages ranged from 5 to 100 . This range was chosen because 5 is the minimum number of events required for the $\chi^{2}$ test, and 100 events is about 2.5 times more events than in the Urlaub et al. (2013) global compilation. It thus captures a reasonable minimum and maximum value for the number of available landslide ages. These patterns were used to examine if we could identify whether the occurrence of landslides in these simulated records was indeed non-random.

\subsubsection{Addition of uncertainties in ages}

Age uncertainties were subsequently applied to the patterns of landslides outlined in Section 2.2 in a number of different ways. First, age uncertainties of up to $\pm 0.75 \mathrm{kyr}$ were applied uniformly to all landslide ages. This was done because $\pm 0.75 \mathrm{kyr}$ represented an age uncertainty large enough for any event to be moved by at least one bin (each bin is $1 \mathrm{kyr}$ ). The choice of limiting uniform error results from the $\chi^{2}$ test assessing the distribution through the use of bins. The use of bins combined with uniform age uncertainty means that the $\chi^{2}$ test is not sensitive to the temporal order of events. Thus, with uniform age uncertainty of $\pm 0.75 \mathrm{kyr}$, events are able to reverse their temporal order, although the $\chi^{2}$ test will not recognise this.

Second, age uncertainties of a random duration between $0 \mathrm{kyr}$ and $3 \mathrm{kyr}$ were applied to events. Both the size of age uncertainty and the event to which it was applied were selected using random number generators. Our choice of a range between 0 and $3 \mathrm{kyr}$ was informed by the uncertainties in age of river fan systems in the Urlaub et al. (2013) study, which have a mean error of $2.34 \mathrm{kyr}$ (Rothwell et al., 1998; Reeder et al., 2000, 2002; Lastras et al., 2004; Maslin et al., 2005; Garziglia et al., 2008; Gracia et al., 2010; Bourget et al., 2011; Masson et al., 2011, 2013). This is the smallest mean uncertainty for any of the settings considered by Urlaub et al. (2013).
Third, ever increasing age uncertainties were applied to events. Age 340 uncertainties increased progressively in accordance with the age of the 341 event that it was being applied to, i.e. the youngest event did not have 342 an age uncertainty whilst the age uncertainty of the oldest event was 343 the largest (see Fig. 4). The largest age uncertainty applied was $20 \mathrm{kyr} 344$ $( \pm 10 \mathrm{kyr}$ ) reflecting the global record used by the Urlaub et al. 345 (2013) study as the greatest age uncertainty present in this record 346 was $19.98 \mathrm{kyr}$ ( $\pm 9.99 \mathrm{kyr}$ ) (Reeder et al., 2002).

\subsubsection{Moving the positions of the 1 kyr bins}

348

Landslide ages were assigned to $1 \mathrm{kyr}$ duration bins (0-1 ka, 1-2 ka, 349 $2-3 \mathrm{ka}$, etc.) in order to produce a histogram of landslide frequency. 350 Urlaub et al. (2013) noted that the position and duration of these bins 351 could affect the analysis. We chose bin durations of $1 \mathrm{kyr}$ for the follow- 352 ing reason; that linking landslide frequency to changing environmental 353 factors, such as sea level variations, necessitates that the bin size is suf- 354 ficiently small to capture the environmental change under consider- 355 ation. In the case of sea level change, $1 \mathrm{kyr}$ bin size is reasonably 356 appropriate (Waelbroeck et al., 2002). The position of the $1 \mathrm{kyr}$ bins 357 was varied during the analysis outlined in Sections 2.2 and 2.2.1 to 358 test the extent to which bin position affects our ability to recognise 359 whether landslides are non-random.

\subsection{Landslides from multiple settings}

We also simulate different landslides coming from multiple settings. 362 Each setting was defined to have a perfectly periodic (non-random) se- 363 quence (Fig. 3a), but with a different return period. For example, one 364 setting was given a uniform recurrence interval of $1.5 \mathrm{kyr}$, another 365 $2 \mathrm{kyr}$, and the third $3.5 \mathrm{kyr}$. Landslide ages from these multiple settings 366 were then combined into one overall catalogue and tested for a tempo- 367 rally random sequence as a single dataset. This was done to simulate the 368 generation of a global record of landslides combining different margin 369 types, including glaciated, fluvial and sediment starved, as was seen in 370 Urlaub et al. (2013) or different geographical margins around one 371 basin (Clare et al., 2014) (Fig. 5). The datasets were then manipulated 372 individually and as a single catalogue, by introducing different size 373 error bars to the landslide ages and changing the position of the $1 \mathrm{kyr} 374$ bins. This methodology was then carried out for the other pattern 375 types seen in Fig. 3. It is important to test the role of multiple settings 376 as global datasets of events will include landslides from multiple differ- 377 ent margin types, whilst basin records will include turbidites derived 378 from landslides which may have different environmental settings.

\subsection{Simulated landslide ages whose frequency is dependent on sea level}

380

A third series of landslide ages were generated to analyse the number 381 of events needed to establish with reasonable certainty that global land- 382 slide frequency is controlled strongly by sea level. The frequency of the 383 landslides in this catalogue was defined to be directly proportional to 384 


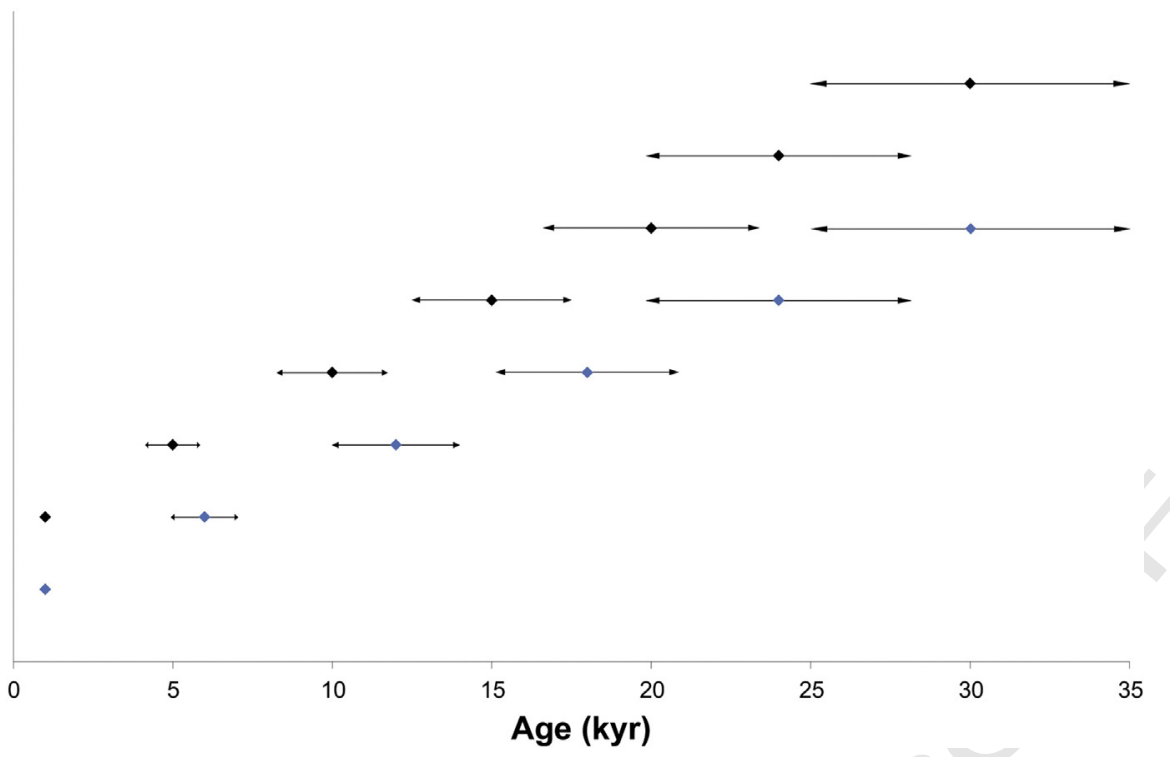

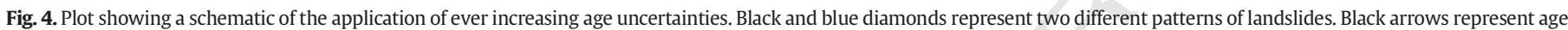
uncertainties which increase as the landslide get older within each pattern.

sea level, using a global eustatic sea level curve for the last $30 \mathrm{ka}$ (Waelbroeck et al., 2002). Event frequency was simulated to be highest during the last $1 \mathrm{ka}$ in accordance with the highest sea level, whilst the lowest frequency occurred around the last glacial maximum $20 \mathrm{ka}$. A directly proportional relationship was chosen in order for there to be the strongest possible relationship between sea level and event frequency; thus it serves to enable us to identify the fewest number of events needed as part of a best case scenario to link the two processes. It also acts as a starting point for linking other processes to landslide occurrence.

This artificial catalogue of landslide ages contained 67 entries, which were numbered from 0 to 66 . We then explored how many events were needed to identify sea level control. Beginning with one event from the catalogue, events were added randomly to our analysis until all 67 were included. This mimics the discovery and dating of submarine landslides through continued field investigations. Bins with durations of $1 \mathrm{kyr}$ are used to order to replicate the precision needed to link event frequency to sea level. The catalogue was chosen to contain 67 events as this is greater than the current global catalogue of well dated landslides for the last 30 ka (i.e. 41 events; Urlaub et al., 2013), whilst being within the same order of magnitude thus acting as a useful comparison to the 405 global landslide record.

2.5. Why choose to investigate landslide frequency proportional to sea 407 level?

We specifically investigate sea level due to its link to current anthro- 409 pogenic climate change and concerns regarding the consequence of fu- 410 ture sea level rise on landslide frequency (Maslin et al., 2004, 2005; 411 Owen et al., 2007; Lee, 2009). Using the global sea level curve for the 412 last 30 ka provides us with the simplest test of how many landslide 413 we would need to date to identify a non-random temporal distribution 414 of events. This $30 \mathrm{kyr}$ time period, used in the Urlaub et al. (2013) study, 415 represents just over half a glacial cycle. Sea level begins the period dur- 416 ing a low stand and rises to the end of the period. When the relationship 417 between sea level and landslide frequency is linearly proportional over 418 the last $30 \mathrm{ka}$, the distribution of landslide ages is a close approximation 419 to a trend distribution (Fig. $3 c$ ). If the $\chi^{2}$ test is unable to identify this re- 420 lationship we are unlikely to be able to identify a relationship between 421 another variable and landslide frequency.

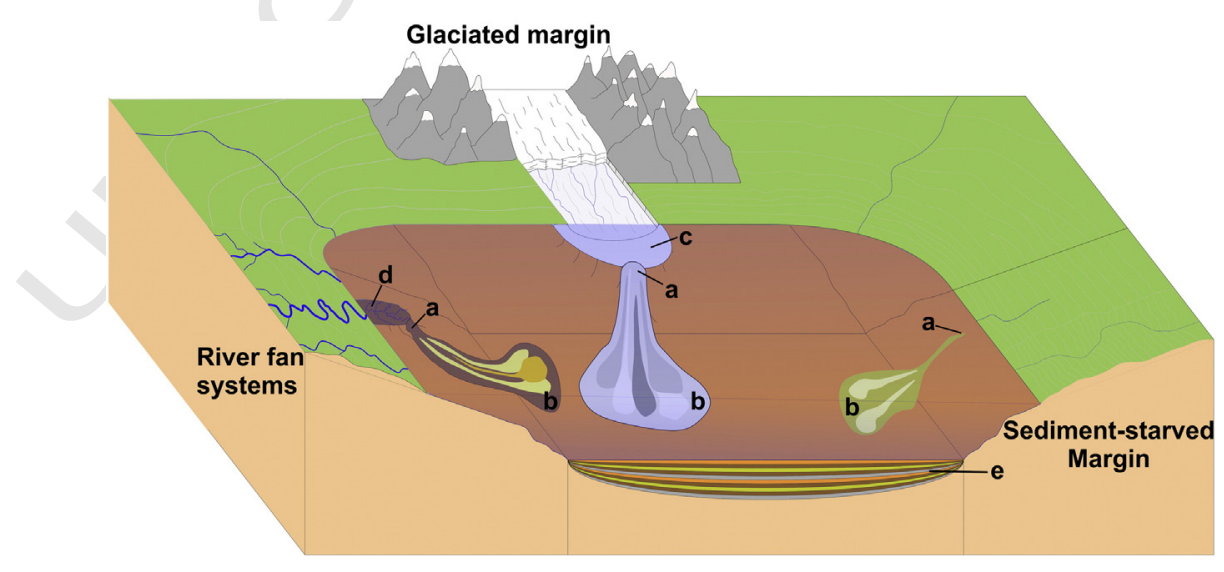

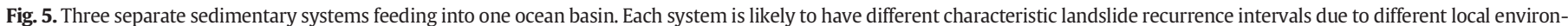

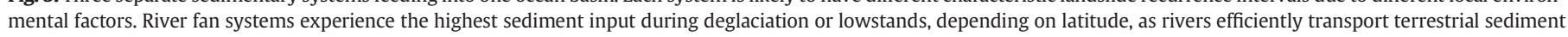

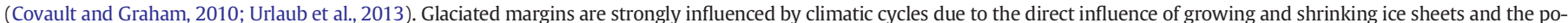

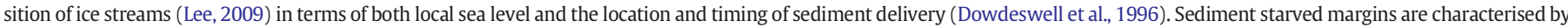

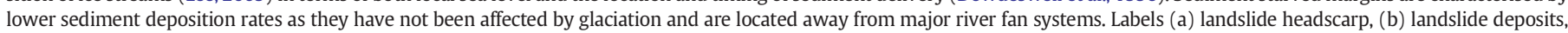
(c) trough mouth fan, (d) river fan delta, (e) interbedded sequence of background hemipelagic and sediment density flow deposits. 
Importantly, whilst we analyse sea level, this analysis is also able to represent a proportionally linear response of landslide frequency to rate of sea level change over the same period. In a catalogue of 67 landslides where landslide frequency was linearly proportional to rate of sea level change, the frequency distribution using $1 \mathrm{kyr}$ bins would be the same as the sea level controlled example. The only difference between the catalogues would be that they are temporally offset from each other. Crucially, the $\chi^{2}$ methodology outlined using bins does not recognise the temporal order of events (see Section 2.2.1.) merely the frequency of events in different bins. The $\chi^{2}$ test used would therefore not recognise any difference between a landslide dataset linearly proportional to sea level and a landslide dataset linearly proportional to sea level change if half or a full sea level cycle is included within the period of study.

\section{Results}

We now address the three main questions that form the aims of this study.

\subsection{Are large landslides temporally random, or are age uncertainties too} large to tell?

\subsubsection{How many perfectly known landslide ages are necessary to show they} are non-random?

Simulated landslide ages were generated for the last $30 \mathrm{ka}$ that were perfectly non-random and whose ages were known perfectly. It was found that when there were over 40 dated landslides in the distribution, we could always correctly determine that landslide occurrence was non-random. Where samples of $>40$ ages were taken from the distribution types, the $\chi^{2}$ statistic allowed us to reject the hypothesis of temporal randomness for all the pattern types.

When samples of $<40$ ages were analysed, the results were more variable. Table 2 contains the results for the iteration of each landslide dataset pattern containing the largest number of events that appeared temporally random according to the $\chi^{2}$ statistic. Each of these patterns is also displayed in Fig. 6 . Here, we show how the $\chi^{2}$ statistic varies as the number of landslides in each pattern changes. The apparent cyclical nature of the $\chi^{2}$ statistic value is a consequence of the methodology using discrete data and the relative numbers of bins with events in them. For example, in Fig. $6 \mathrm{a}$ the $\chi^{2}$ statistic is sensitive to the relative numbers of events in each bin, i.e. how many bins contain 2 landslides and how many contain 3 . The $\chi^{2}$ statistic therefore peaks when all of the bins have the same number of events in before declining until 50\% of the bins contain one number of landslides while the other $50 \%$ contain a different number of landslides. The $\chi^{2}$ statistic subsequently rises as the percentage of bins with the same number within them increases.

Perfectly periodic distributions were only considered random when the event dataset contained 14 events or fewer (Fig. 6a). At 14 ages the event dataset returned a critical value of 3.814 which was below the critical $\chi^{2}$ value of 3.841 at the $95 \%$ confidence interval. The likelihood ratio statistic supports identification of this distribution as random; 0.663 is well below the critical value of 3.841. Non-random landslide datasets with linearly increasing inter-event times were considered random when they contained 17 ages or fewer (Fig. 6c). Considering 17 ages the dataset returned a critical value of 3.212 which was below the critical $\chi^{2}$ value of 3.841 at the $95 \%$ confidence interval. The likelihood ratio (0.553 does not exceed the critical value of 3.841), 477 which supports this evaluation.

The relationship between number of events and the ability of the $\chi^{2} 479$ statistic to recognise non-random recurrence of events was found to be 480 more complicated for clustered and patterned datasets and showed an 481 important influence of bin position. For clustered landslide patterns, 482 the $\chi^{2}$ statistic considered datasets with 14 events or fewer to be tempo- 483 rally random. For a dataset containing 14 ages, the $\chi^{2}$ critical value was 484 3.525 which was below the critical value of 3.841 required to show non- 485 randomness. The maximum number of ages as part of a clustered 486 dataset of landslide ages which was considered random was 37487 (Fig. 6b). The $\chi^{2}$ statistic returned for the clustered dataset containing 488 37 ages was 2.798 compared to the critical value of 3.841. The likelihood 489 ratio supports this interpretation although its value (3.423) is almost at 490 parity with the critical value (3.841). This suggests that small changes 491 could alter the interpretation of the distribution which supports the 492 range of distributions interpreted for patterns containing between 14493 and 37 ages. Datasets containing between 14 and 37 ages were also 494 often considered random. However, movement of the $1 \mathrm{kyr}$ bins result- 495 ed in many of these datasets being shown to be temporally non- 496 random.

The range of patterned (Fig. 3d) landslide age datasets considered 498 temporally random exceeded that demonstrated by the clustered 499 datasets. No patterned dataset with 14 ages or fewer could be discerned 500 from a random distribution. However, a dataset with 39 patterned ages 501 could not be accepted as different to a random distribution according to 502 the $\chi^{2}$ statistic (Fig. 6d). It had a $\chi^{2}$ critical value of 4.94 which was less 503 than the 5.991 critical value required to be considered non-random at 504 the $95 \%$ confidence interval (the likelihood ratio value was 2.829 com- 505 pared to a critical value of 5.991). The $\chi^{2}$ statistic considered different 506 patterned landslide age datasets containing between 14 and 39 events, 507 which were both temporally random and non-random. For many 508 datasets the position of the bins was crucial. It was found that move- 509 ment of the bins often altered whether the dataset was considered tem- 510 porally random at the $95 \%$ confidence interval.

\subsubsection{Introduction of more realistic uncertainties (error bars) in landslide 512} ages

We first introduced uniform age uncertainties of up to $\pm 0.5 \mathrm{kyr}$ to 514 the four different non-random landslide age patterns. In each case we 515 considered more than 40 landslide events. This did not produce any 516 submarine landslide age distributions that appeared temporally ran- 517 dom according to the $\chi^{2}$ statistic. Similarly, the introduction of error 518 bars in landslide ages between $\pm 0.25 \mathrm{kyr}$ and $\pm 0.75 \mathrm{kyr}$ produced, 519 with the exception of a number of patterned landslide age datasets, no 520 distributions which appeared temporally random with $>40$ landslides. 521

In some cases it was found that movement of the bins resulted in the 522 patterned landslide age datasets appearing to be non-random, which 523 had previously been determined as random. For example, movement 524 of the $1 \mathrm{kyr}$ bins resulted in the same dataset, with 55 ages, having $\chi^{2} 525$ values of between 12.121 and 7.533 with the $\chi^{2}$ critical value being 526 9.488 (the likelihood-ratio test for these examples being 4.535 and 527 3.427 respectively). This implies that as age uncertainties increase the 528 $\chi^{2}$ test becomes increasingly sensitive to bin position due to its inability 529 to recognise temporal order.

The impact of age uncertainties of $\pm 0.75 \mathrm{kyr}$ on landslide patterns is 531 shown in Fig. 7. Here, we show the impact of \pm 0.75 kyr on the $\chi^{2}$ value 532 to the landslide patterns shown in Fig. 6. Fig. 7a-d all show that age 533

Table 2

$\chi^{2}$ and likelihood ratio results for landslide age patterns containing the greatest number of events with no age uncertainties which appear to be random according to the $\chi^{2}$ test.

\begin{tabular}{|c|c|c|c|c|c|c|c|c|}
\hline Perfectly periodic & 14 & $16(17.60)$ & $14(9.39)$ & $0(2.50)$ & $0(0.444)$ & 3.841 & 2.9063 & 0.663 \\
\hline Clustered & 37 & $10(8.74)$ & $8(10.78)$ & $7(6.65)$ & $5(12.73)$ & 3.841 & 2.7982 & 3.423 \\
\hline Linearly increasing inter-event times & 17 & $15(17.02)$ & $14(9.65)$ & $0(2.73)$ & $1(0.516)$ & 3.841 & 3.212 & 3.744 \\
\hline Patterned & 39 & $6(8.16)$ & $15(10.63)$ & $5(6.91)$ & $4(2.99)$ & 5.991 & 4.94 & 2.829 \\
\hline
\end{tabular}


a)

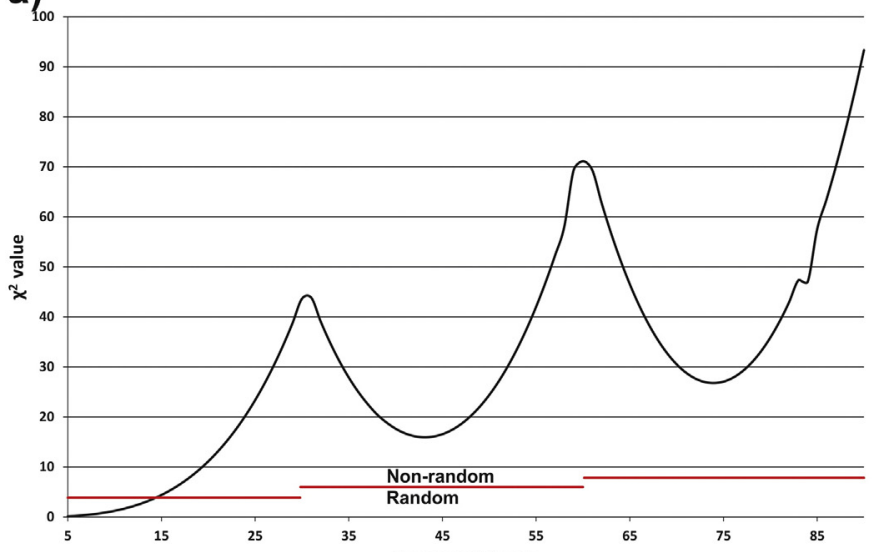

b)

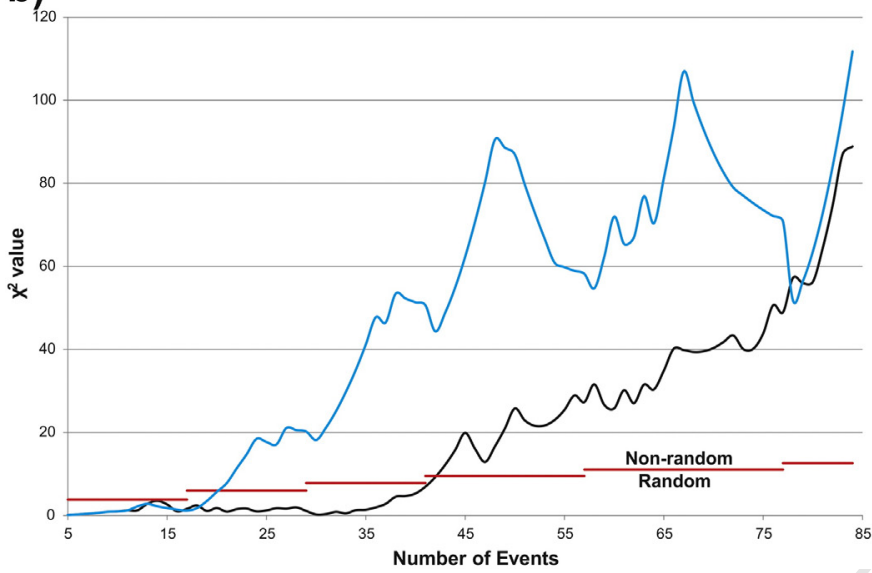

c)

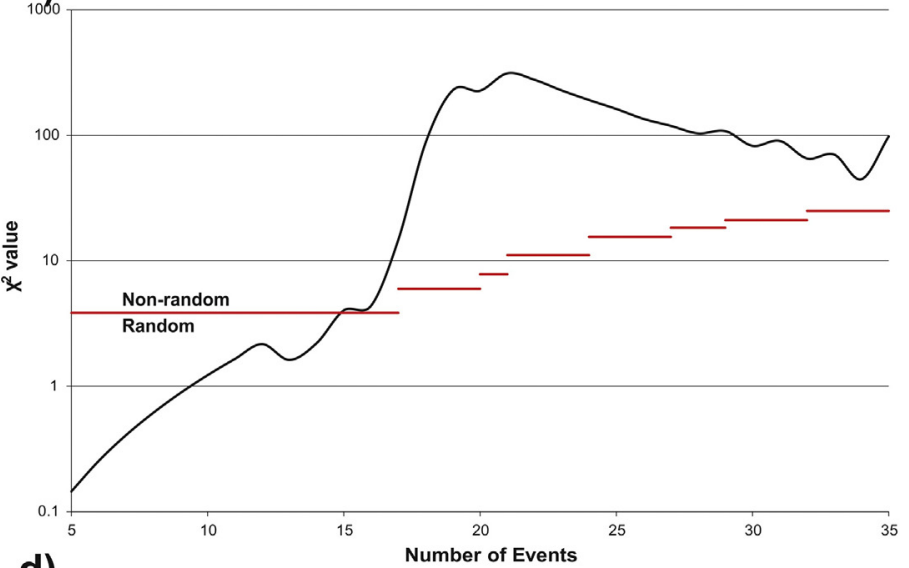

d)

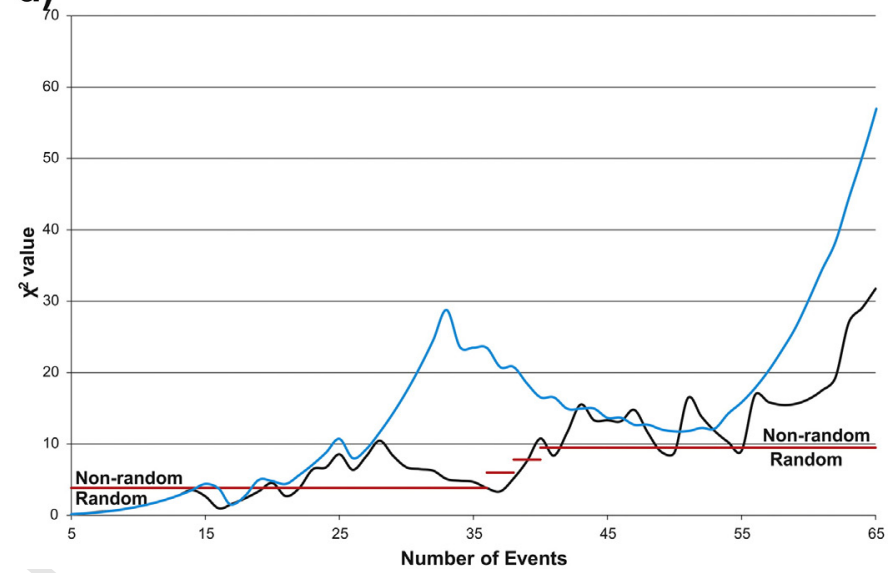

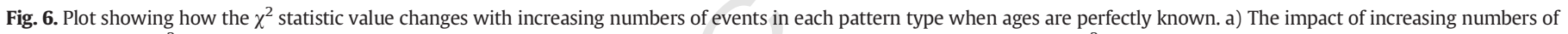

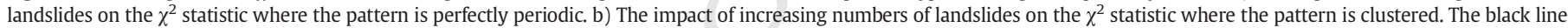

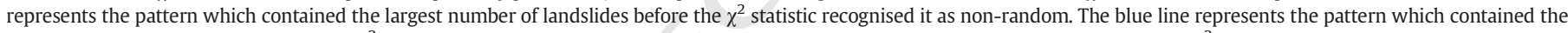

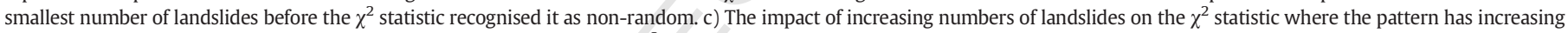

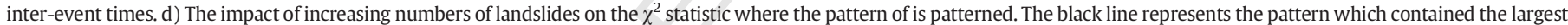

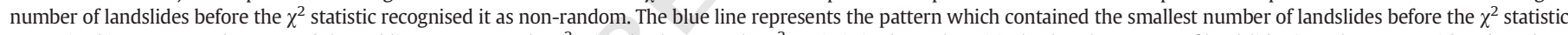

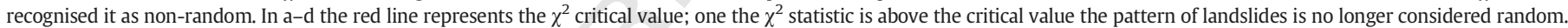
(For interpretation of the references to colour in this figure legend, the reader is referred to the web version of this article.)

uncertainty can reduce the $\chi^{2}$ statistic value of non-random patterns. However, Fig. 7a, b and d all show that where patterns of landslides contain relatively few events, the response to the age uncertainty can be for the pattern to increase the $\chi^{2}$ statistic value and thus appear much less random than when the pattern had no age uncertainty associated with it. Fig. 7c implies that where patterns of landslides have linearly increasing inter-event times the impact of introducing age uncertainties is primarily to reduce the $\chi^{2}$ statistic value.

Further analysis of larger error bars in landslide ages involved two approaches. First, randomly generated age uncertainties of between $0 \mathrm{kyr}$ and $3 \mathrm{kyr}$ were assigned to events randomly using a random number generator. This allowed us to define the threshold number of landslide events, which have a certain age uncertainty, that are needed to make non-random landslides appear temporally random. This threshold number of landslides with age uncertainties varied depending on the original pattern (periodic, clustered, etc.) and the number of events within the pattern. Second, it was assumed that age uncertainties increased linearly for progressively older landslides up to $20 \mathrm{kyr}$. This approach resulted in almost all of the datasets we considered, appearing temporally random. The apparent randomness was caused predominately by the larger age uncertainties (up to $20 \mathrm{kyr}$ ) on the older landslides in each distribution.

Urlaub et al. (2013) considered 41 landslide ages in the last $30 \mathrm{kyr}$ from a series of different settings. The 24 examples from river fed systems have the smallest average error bars (2.34 kyr). Their landslide 558 ages from other settings have even larger error bars. Our analysis there- 559 fore shows that the inclusion of realistic error bars, even those from the 560 better dated river fed systems, can cause non-random landslide ages to 561 appear random.

3.1.3. Can combination of multiple non-random sets of landslide ages lead 563 to temporal randomness?

564

We now address our second aim; how easy is it to produce random 565 landslide ages by combining non-random ages from multiple settings? 566 Three different, artificially generated, perfectly periodic non-random 567 distributed (Fig. 3a) landslide datasets were combined and analysed 568 by the $\chi^{2}$ statistics. The combined dataset often appeared to be tempo- 569 rally random. The occurrence of an apparently temporally random dis- 570 tribution is the result of the three sources being out of phase with one 571 another. Phase is defined here as the timing of events within a time se- 572 ries. For two perfectly periodic distributions (see Fig. 3a) with recur- 573 rence intervals of $1 \mathrm{kyr}$ for both distributions, the distributions would 574 be considered in phase if events in both distributions occurred at the 575 same time (i.e., 1 st event at $0.5 \mathrm{ka}$, 2 nd event at $1.5 \mathrm{ka}$, etc.). They 576 would be considered out of phase if they occurred at different times 577 (i.e., for the first distribution events occurred at $0.5 \mathrm{ka}, 1.5 \mathrm{ka}, 2.5 \mathrm{ka}, 578$ etc.; for the second distribution event occurred at $0.3 \mathrm{ka}, 1.3 \mathrm{ka}, 2.3 \mathrm{ka}, 579$ etc.). The overlaying of ordered patterns appears to generate 580 

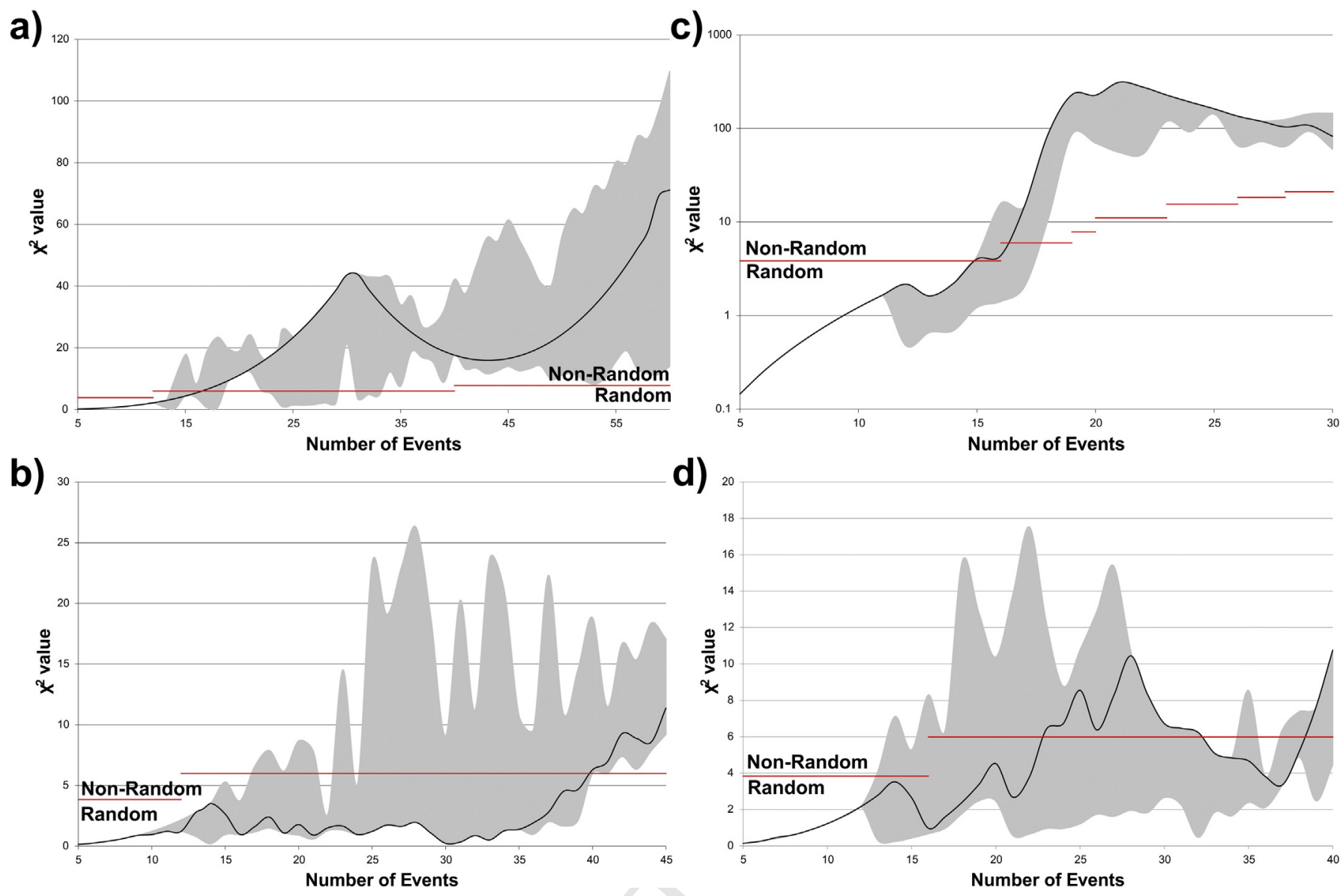

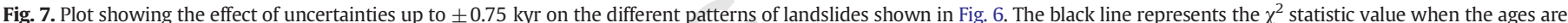

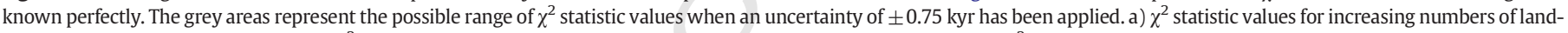

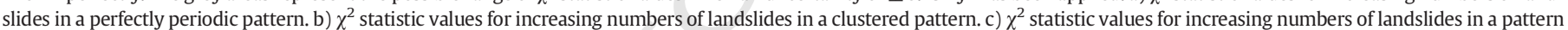

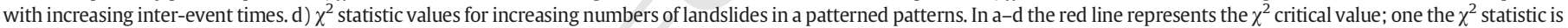

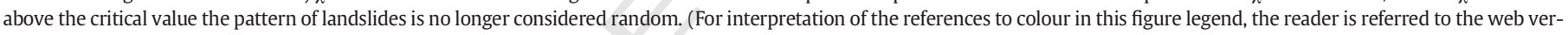
sion of this article.)

randomness. Conversely, when perfectly periodic landslide ages were in phase, the distribution of the combined dataset was not perceived to be random.

Age uncertainties were applied, both uniformly across three perfectly periodic landslide datasets and to individual datasets. The latter was intended to replicate the different sized age uncertainties associated with the various margin types seen in Urlaub et al. (2013). Addition of age uncertainty to any or all of the records acted to make the distribution of events appear more temporally random.

This methodology was also applied to the other patterns of landslide ages seen in Fig. 3, in addition to combining datasets with different patterns of landslide ages. The same results were found when three landslide age patterns of the same type were combined. The same was also true when multiple landslide age pattern types were combined. However, assessment of whether one age pattern was in phase with another was problematic.

3.2. How many landslide ages are needed to test for a strong dependency on sea level?

To determine the power of the test we performed a series of model iterations. Random introduction of landslides resulted in the distribution of landslide ages appearing temporally random and non-random depending on the order that event were introduced. An example run presented in Table 3. After 23 events are introduced in the example run, the distribution appears to be non-random. However, addition of another (24th) event then causes the distribution to appear to be ran- 605 dom. Only after 28 events does the distribution remain non-random 606 with the additional of further events. We thus recorded the number of 607 events required before the distribution that did not revert to being ran- 608 dom following the addition of further events.

Our results showed that the number of ands a non-random distribution at the $95 \%$ confidence interval was highly 611 variable. The mean number required was 38. However, the range of 612 landslides needed was from 10 to 53, with the variability between dif- 613 ferent iterations being shown by a standard deviation of 8.34; a large 614 figure when compared to the size of the dataset.

These results show that 10 to 53 landslide ages are needed with a 616 mean of 38 ages, when the landslide age is known perfectly to show a 617 strong dependency on sea level. 95\% of landslide age distributions 618 were correctly identified as non-random when they had 48 ages. How- 619 ever, the ages from real submarine landslides have are not perfectly 620 dated and have associated error bars (Urlaub et al., 2013). When these 621 uncertainties are added the number of landslides required to identify 622 a strong sea level dependency will be greater than the number shown 623 here.

\section{Discussion}

We first discuss the implications of the answers to our three aims 626 (Sections 4.1, 4.2 and 4.3), and then outline the main sources of uncer- 627 tainty in linking landslide ages and sea level (Section 4.4). Section 4.5628 
Table 3

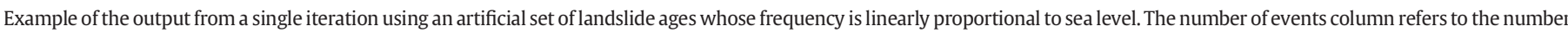

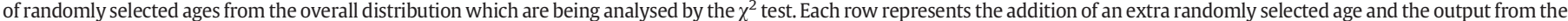

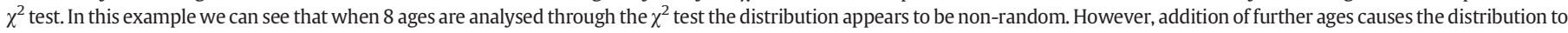

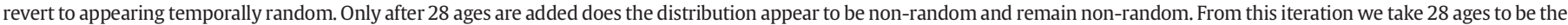
number of ages required for the $\chi^{2}$ test to recognise the distribution is in fact non-random. $O_{j}=0 \ldots .4$ is the number of bins observed with $n$ ages.

\begin{tabular}{|c|c|c|c|c|c|c|c|c|c|}
\hline Number of events & $\begin{array}{l}\text { How the chi-square test views the landslide } \\
\text { ages at the } 95 \% \text { confidence interval }\end{array}$ & Chi-squared value & $\begin{array}{l}\text { Critical } \\
\text { value }\end{array}$ & $\mathrm{Oj}=0$ & $\mathrm{Oj}=1$ & $\mathrm{Oj}=2$ & $\mathrm{Oj}=3$ & $\mathrm{Oj}=4$ & Likelihood-ratio \\
\hline 5 & Random & 0.136 & 3.841 & 26 & 5 & & & & 0.036 \\
\hline 6 & Random & 0.237 & 3.841 & 25 & 6 & & & & 0.452 \\
\hline 7 & Random & 0.38 & 3.841 & 24 & 7 & & & & 0.497 \\
\hline 8 & Non-random & 13.449 & 7.815 & 24 & 6 & & 1 & & 0.183 \\
\hline 9 & Non-random & 9.658 & 7.815 & 23 & 7 & & 1 & & 5.112 \\
\hline 10 & Random & 7.343 & 7.815 & 22 & 8 & & 1 & & 16.409 \\
\hline 11 & Random & 4.508 & 7.815 & 22 & 7 & 1 & 1 & & 2.301 \\
\hline 12 & Random & 3.332 & 7.815 & 21 & 8 & 1 & 1 & & 1.961 \\
\hline 13 & Random & 2.565 & 7.815 & 21 & 7 & 2 & 1 & & 1.711 \\
\hline 14 & Random & 1.701 & 7.815 & 20 & 8 & 2 & 1 & & 1.179 \\
\hline 15 & Random & 1.165 & 7.815 & 19 & 9 & 2 & 1 & & 0.867 \\
\hline 16 & Random & 0.905 & 7.815 & 18 & 10 & 2 & 1 & & 0.760 \\
\hline 17 & Random & 0.628 & 7.815 & 19 & 9 & 3 & 1 & & 2.575 \\
\hline 18 & Random & 1.18 & 7.815 & 18 & 8 & 4 & 1 & & 1.184 \\
\hline 19 & Random & 2.416 & 7.815 & 18 & 7 & 5 & 1 & & 2.444 \\
\hline 20 & Random & 3.683 & 7.815 & 18 & 7 & 4 & 2 & & 2.892 \\
\hline 21 & Random & 4.616 & 7.815 & 18 & 6 & 5 & 2 & & 4.229 \\
\hline 22 & Random & 6.156 & 7.815 & 18 & 5 & 6 & 2 & & 6.212 \\
\hline 23 & Non-random & 8.123 & 7.815 & 18 & 5 & 5 & 3 & & 6.964 \\
\hline 24 & Random & 6.199 & 7.815 & 17 & 6 & 5 & 3 & & 5.058 \\
\hline 25 & Non-random & 9.599 & 7.815 & 17 & 6 & 4 & 4 & & 6.677 \\
\hline 26 & Random & 7.762 & 9.488 & 17 & 6 & 4 & 3 & 1 & 6.572 \\
\hline 27 & Random & 7.582 & 9.488 & 17 & 5 & 5 & 3 & 1 & 6.359 \\
\hline 28 & Non-random & 10.925 & 9.488 & 17 & 5 & 5 & 2 & 2 & 4.011 \\
\hline 29 & Non-random & 11.697 & 9.488 & 17 & 4 & 6 & 2 & 2 & 6.447 \\
\hline 30 & Non-random & 12.081 & 9.488 & 17 & 4 & 5 & 3 & 2 & 6.932 \\
\hline 31 & Non-random & 17.166 & 9.488 & 17 & 4 & 5 & 2 & 3 & 5.378 \\
\hline 32 & Non-random & 17.325 & 9.488 & 17 & 4 & 4 & 3 & 3 & 6.254 \\
\hline
\end{tabular}

outlines the most effective strategy for dating landslides, and thus the best way forward.

4.1. Do available dates show that large landslides are random, or are error bars too large?

As might be expected, our results indicated that it was extremely difficult to make non-random patterns of perfectly dated landslides appear temporally random. However, the smallest error bars in the Urlaub et al. (2013) dataset were for 24 river fed systems, with other settings tending to have much larger error bars in landslide ages. We show that such realistic ( $\pm 3 \mathrm{kyr}$ ) error bars resulted in the appearance of random ages, even when landslides were non-random. Thus, the error bars in Urlaub et al. (2013) are too great to tell if these 41 events represent truly random landslides.

\subsubsection{The additional impact of bins in making landslides appear temporally} random

Additional important errors were introduced into the assessment of whether the events were temporally random by the position of the bins. Bin choice in terms of both width and position is subjective. Therefore it is necessary to vary the position of the bins, up to the bin width in order to assess links between landslides and sea level. Bin width should be chosen depending on the rate of variation in the environmental record (e.g. sea level) with which event frequency is being compared. Bin use, however, remains unavoidable when assessing the statistical distribution of events in a global record (discrete data). Unlike outcrop or single core records, there is no control on the temporal order of events in the global record as deposits do not lie on top of one another. This is compounded by large age uncertainties making the exact temporal order of events unknown. We are therefore unable to use recurrence intervals (continuous data) as the exact relationship between events cannot be specified meaning we are forced to use statistical tests on the frequency of events within 659 certain specified periods of time, i.e. bins.

\subsection{Effects of combining landslide ages from different settings}

661

We demonstrate that three non-random collections of landslide 662 ages could, once combined, appear to be temporally random (Figs. 5663 and 8). More formally, a time-independent, memoryless (Poisson) dis- 664 tribution can result from non-uniform additive influences, as docu- 665 mented by van Rooij et al. (2013). This is likely to be the case for 666 global landslide databases (Urlaub et al., 2013), and it may be the case 667 for studies based on large-volume turbidites in a single basin centre 668 (Clare et al., 2014). This conclusion is important as it suggests that a 669 combination of landslide ages from a small number $(\geq 3)$ of settings 670 can easily produce a single set of apparently random ages.

\subsubsection{Implications for global databases of landslide ages}

672

The global record arguably includes landslides from at least three 673 fundamentally different settings; river-fed systems, ice-stream-fed 674 trough mouth fans and sediment starved margins (Fig. 5). It is very 675 likely that the relationship between sediment supply and sea level, 676 and hence landslide preconditioning, will vary significantly in these 677 three settings (Fig. 5; Laberg et al., 2000, 2003; Covault and 678 Graham, 2010; Llopart et al., 2014). Therefore when combined into 679 one record, if the events are out of phase, a temporally random distri- 680 bution of events is likely. Large age uncertainties will only act to 681 increase the likelihood of such a random distribution in global 682 datasets that consider multiple settings. This suggests that global 683 compilations, or even regional compilations with multiple settings, 684 may not be very useful in determining links between sea level and 685 landside frequency. 

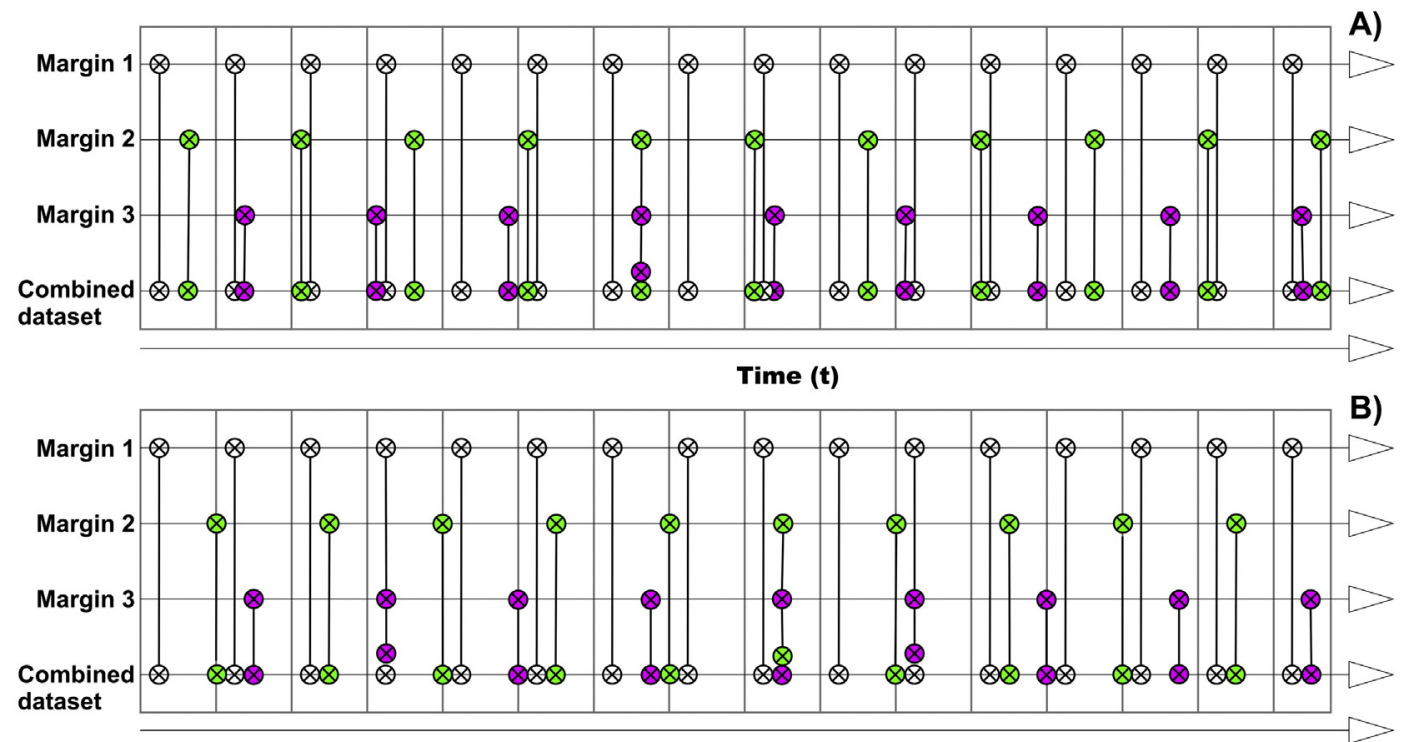
dataset

Time (t)

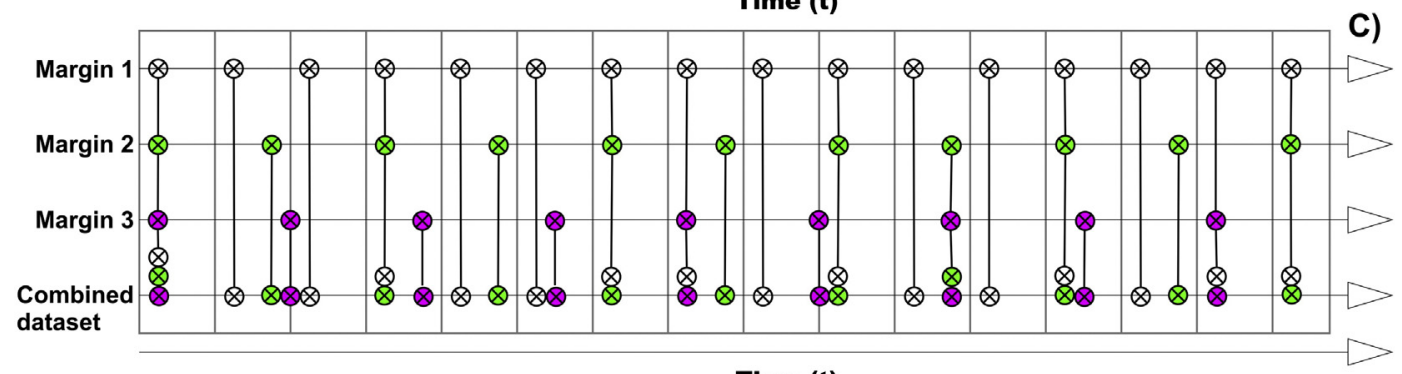

Time (t)

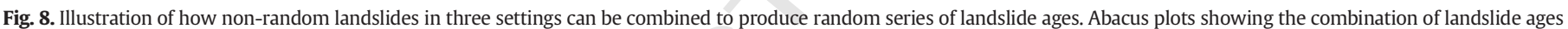

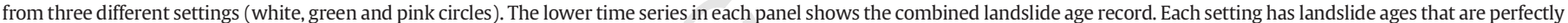

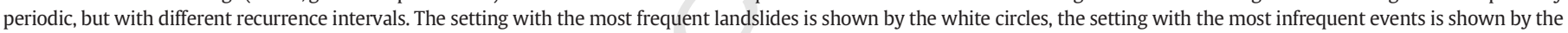

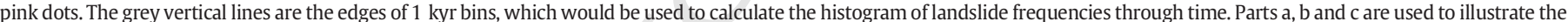

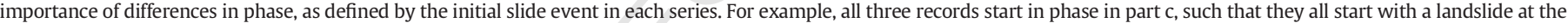

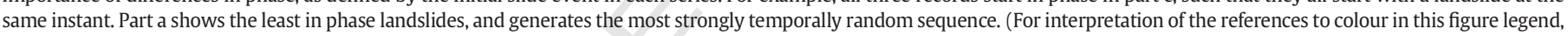
the reader is referred to the web version of this article.)

\subsubsection{Implications for landslide-turbidite records from a single basin}

An alternative approach is to use large turbidites in a single basin, as a proxy for large submarine landslide around the basin margin (Clare et al., 2014; Hunt et al., 2013). However, our study emphasises the importance of understanding the different sources of landslide triggered turbidity currents, if they are out of phase (Rothwell et al., 1998, 2006; Talling et al., 2007; Hunt et al., 2013). Additional effort will also have to be made to clearly identify the difference between landslide and flood triggered turbidites but also to identify where large turbidity currents have been generated by the coalescence of multiple small failures. Inclusion of turbidites in the database that have not been generated by large $\left(>1 \mathrm{~km}^{3}\right)$ events will likely weaken any statistical relationship within a database.

\subsection{How many landslides are needed to identify a strong sea level control?}

If landslide frequency is linearly proportional to sea level, our study shows that 10 to 53 perfectly dated landslides are needed to statistically identify that direct correlation. It follows that considerably more than 10 to 53 landslides (mean 38) will be needed once age uncertainties are included. However, two other issues are relevant to this discussion.

\subsubsection{Controlling factors with more distinctive patterns than sea level}

First, further work is needed to determine how many landslides should be dated, if landslide frequency is proportional to rate of sea level change, and not absolute sea level. More generally, a smaller num- 709 ber of landslides may need to be dated if the controlling factor has a 710 more distinctive pattern through time. Some types of controlling factors 711 may have a more distinctive pattern of variation than near sinusoidal 712 sea level, or occur infrequently. In such cases, a smaller number of land- 713 slide ages may be needed to test for statistically significant relationships 714 with landslide frequency. For instance, the Storegga Slide is near syn- 715 chronous with the last major very abrupt climate change, the $8.2 \mathrm{ka}$ cli- 716 mate event (Haflidason et al., 2005; Dawson et al., 2011). Landslide 717 frequency has also been linked to infrequent periods of very rapid sea 718 level rise (Brothers et al., 2013; Smith et al., 2013). Events of this type 719 are relatively rare and short-lived. A different approach may be needed 720 to determine how many landslides should be dated to see if there is a 721 link to such events.

4.3.2. Stronger proportionality between landslide frequency and sea level 723

A second issue is that we assume that landslide frequency is directly 724 proportional to sea level, such that the constant proportionality is unity. 725 It is possible that a much stronger association exists, such that the 726 constant proportionality is far greater than unity. In such a situation, a 727 smaller number of landslides may be needed to test for a significant 728 association with sea level.

Sea level itself presents challenges for finding a statistical relation- 731 ship with landslide frequency at a global scale. Local sea level change 732 
can be very different from global eustatic sea level change due to glacioisostasy and local tectonic influences (Lambeck et al., 1998; MurrayWallace, 2002). Additional uncertainty arises because of our limited ability to reconstruct accurate local sea level curves. Combined with delayed responses, either to changes in sea level or other identified triggering factors, this reduces the likelihood of linking event to cause. Modelling studies have indicated that continental slopes may have site-specific delayed responses to earthquake triggers (L'Heureux et al., 2013). Delayed and variable response to slow forcing mechanisms such as sea level rise is therefore likely to be even more inconsistent geographically. Submarine landslides from the global catalogue of Urlaub et al. (2013) with relatively well constrained dates are confined to one glacial sea level cycle. Dating of additional events which occurred during other glacial cycles may improve our ability to link events to changes in sea level.

\subsection{Implications for studying landslides older than $30 \mathrm{ka}$}

Several reasons may make it problematic to study landslides older than 30 ka. First, as noted by Urlaub et al. (2013), cores from the modern seafloor may not penetrate deeply enough to reach older events. Second, the error bars in landslide ages tend to increase significantly with time (Fig. 1), especially once landslides become too old to date via radiocarbon (> 43 ka). However, a third reason may also be important.

\subsubsection{Non-stationary random triggers whose average recurrence rate} varies over time

We have presented a statistical analysis of perfectly non-random landslides and tested the number of landslides that would be required in order to identify non-randomness. However, the testing of these landslide patterns represents an idealised non-random case for two reasons. First, the triggering mechanisms for these events will likely add a random component to these regular patterns. The addition of a degree of randomness, combined with age uncertainties will likely lead to the non-random nature of these events being harder to discern.

Second, landslides may be occurring according to a non-stationary Poisson process. The time period considered within this study is relatively short at geological timescales. The shortness of the time period in question means that the distribution of some random events appears stationary, such that the mean recurrence rate of landslides does not change over time. However, over longer time periods, although remaining inherently random, the mean recurrence rate may change. Such processes are considered to be occurring according to a non-stationary Poisson process, i.e. occurring in clusters (Fig. 3b). Earthquakes represent an example of a non-stationary Poisson process. Over short time periods they have a near-random distribution. Over longer time periods the mean recurrence rate may change as fault systems more or tectonic settings evolve. For submarine landslides, triggering processes are likely to be affected by large-scale environmental change associated with climate change leading to fluctuations in triggering (Geist and Parsons, 2009).

Inherent randomness caused by specific triggers and nonstationarity of Poisson processes mean that the results of this study are somewhat idealised. These results thus represent a best case scenario for recognising non-randomness using the statistical methodology that has been outlined. Detection of a non-stationary Poisson process is not attempted here, and it would be more challenging, and could require many more events than are in Urlaub et al.'s (2013) database. Evaluation of a non-stationary Poisson process for large submarine landslides is difficult, but should be the subject of future work.

\subsection{Future strategies for dating submarine landslides - what is the best} way forward?

We have shown that realistic error bars in landslide dating, and combination of ages from as few as three different settings, make it difficult to test for links between sea level and landslide frequency. The most 794 complete global compilation of 41 large landslide ages in the last 795 30 ka appears temporally random (Urlaub et al., 2013), but could plau- 796 sibly result from non-random processes such as sea level. We currently 797 have too few well-dated landslides to test for a linear dependence be- 798 tween landslide frequency and sea level, even using better constrained 799 sub-sets of those landslide ages from river fed systems (Urlaub et al., 800 2013). Although we would be able to test for a stronger (i.e. non- 801 linear) dependence on sea level, or indeed links to events with more 802 distinctive time series, such as abrupt climate warming or sea level 803 rise events. However, these negative conclusions raise the issue; what 804 is the most constructive way forward?

4.5.1. Testing scientific hypotheses — are negative results useful? 806

We first note that it is useful to know the answer to scientific ques- 807 tions, even when they are negative answers. This helps us to narrow 808 down avenues of future research, and avoid misleading conclusions, 809 such as that currently available landslide ages show a significant corre- 810 lation with sea level. Indeed, a broad comparison might be made to 811 medical trials, in which there is a detrimental bias towards publications 812 of positive tests (Goldacre, 2010).

4.5.2. Importance of using quantitative and robust statistical methods 814

Previous workers have proposed a number of different relationships 815 between sea level and landslide frequency, based on qualitative analy- 816 ses. They include a relationship between landslides and low sea level 817 (Paull et al., 1996), rising or low sea level (Lee, 2009), or indeed no rela- 818 tionship with sea level (Urlaub et al., 2013). This study illustrates the 819 importance of quantitative statistical techniques to understand what 820 is significant in such datasets.

821

More sophisticated statistical methodologies can be used. For exam- 822 ple treating submarine landslide hazards in a similar evidence-based 823 manner to large magnitude volcanic and earthquake hazards (Aspinall 824 et al., 2003; Baxter et al., 2008; Daub et al., 2012). Evidence-based refers 825 to a methodology where the examination of evidence from specific 826 studies and the systematic collection of this evidence are highly weight- 827 ed in decision making; intuition and unsystematic experience are de- 828 emphasised (Sackett et al., 1996). Evidence based hazard analysis, first 829 used in medicine (Aspinall et al., 2003) and subsequently used on Mont- 830 serrat from 1997 (Baxter et al., 2008), incorporates all available theoret- 831 ical and observational information and applies probabilistic procedures 832 using Bayesian statistics. This allows decision making that is open to re- 833 vision with partial or imperfect information as the degree of evidence 834 uncertainty is weighted accordingly (Baxter et al., 2008). Hazard assess- 835 ment should therefore attempt to incorporate well dated landslides, in- 836 cluding those whose ages are near abrupt climatic events whilst also 837 including extreme value theory statistics (Sornette, 2009; Dawson 838 et al., 2011; Bondevik et al., 2012).

4.5.3. Should there be a wider spread of dated landslides to avoid spatially 840 biased compilations?

The current global compilation of landslides ages is spatially biased 842 (Urlaub et al., 2013). Large submarine landslides have predominantly 843 been catalogued in certain areas, such as the North Atlantic, Iberian 844 Margin, and Mediterranean (Fig. 9) (Urlaub et al., 2013). International 845 efforts could therefore attempt to broaden the area where events are 846 dated, and avoid such strong geographical biases. However, this might 847 not be the most productive strategy as it will result in the combination 848 of landslide ages from an even wider range of settings. As we show here, 849 a greater number of settings may be very likely to generate apparently 850 random age sequences from non-random triggers (Figs. 5 and 9). 851

4.5.4. Concentration of dating efforts at a small number of similar settings 852 with long records

Our study suggests that efforts may need to be concentrated, such 854 that statistically significant numbers of well-dated landslides are 855 


\begin{tabular}{|c|c|c|c|}
\hline $\begin{array}{l}\text { Global Record } \\
\text { Record length: } 30 \mathrm{ka} \\
\text { Number of events: } 41 \\
\text { Return period: ? }\end{array}$ & Global record & $\begin{array}{l}\text { Event composition } \\
\text { events with no physical } \\
\text { constraint on which event is } \\
\text { oldest as events occur in } \\
\text { separate records }\end{array}$ & $\begin{array}{l}\text { Issues with record } \\
\text { Geographical bias } \\
\text { Temporally limited } \\
\text { Limited by sample size }\end{array}$ \\
\hline $\begin{array}{l}\text { Regional Record } \\
\text { Record length: } \geq 250 \mathrm{ka} \\
\text { Number of events: }>100 \\
\text { Return period: } \geq 1000 \mathrm{a}\end{array}$ & $\begin{array}{l}\text { Turbidites generated from disparate } \\
\text { locations sampled using multiple } \\
\text { deep sediment cores (blue arrows } \\
\text { indicate source direction }\end{array}$ & $\begin{array}{l}\text { Regional core } \\
\text { correlation } \\
\text { Turbidite deposits may be missing } \\
\text { from one or more of the cores } \\
\text { ore to bypass, erosion, collapse } \\
\text { or extent }\end{array}$ & $\begin{array}{l}\text { Issues with record } \\
\text { Limited to size >0.1 } \mathrm{km}^{3} \\
\text { i.e. flows of sufficient size } \\
\text { to reach the basin } \\
\text { Overprinting of signal } \\
\text { i.e. multiple sources with } \\
\text { possibly varying signals }\end{array}$ \\
\hline $\begin{array}{l}\text { Local Record } \\
\text { Record length: Core dependent } \\
\text { Number of events: }<10 \\
\text { Return period: location dependent }\end{array}$ & $\begin{array}{l}\text { Sampling method } \\
\text { of local data }\end{array}$ & $\begin{array}{l}\text { Core correlations } \\
\text { Landslide deposit may be missing } \\
\text { from one or more of cores due to } \\
\text { core depth, deposit depth, extent, etc }\end{array}$ & $\begin{array}{l}\text { Issues with record } \\
\text { Typically limited to } 1-2 \text { slides } \\
\text { Age constraints/dating errors } \\
\text { Limited by core depth }\end{array}$ \\
\hline
\end{tabular}

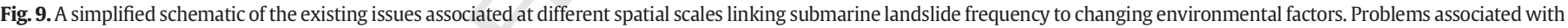
each of the different records have emerged as introducing significant error during different parts of this study.

obtained from individual types of setting. To achieve this, controlling variables need to be isolated; something the use of disparate records may prevent (McAdoo and Watts, 2004; Brothers et al., 2013). Perhaps the simplest means of advancing knowledge is to focus specifically on river fed systems (Covault and Graham, 2010). River fed systems have both the greatest number of catalogued events, as well as the smallest age uncertainties (Urlaub et al., 2013). They are also the margin type where glacial cycles have been suggested to play a particularly important role, via sediment supply (Covault and Graham, 2010). Identification of additional events at these margins therefore provides the greatest likelihood of asserting, with some degree of confidence, the effects of sea level on landslide frequency (Geist et al., 2013). This could be achieved through either IODP sites or long basin core records where the input sources to the basin are well constrained. Focusing on one of these record types and isolating local environmental factors such as local sea level change would allow for a more useful comparison of landslide frequency and sea level change. However, care will still be needed to be taken to distinguish the effects of glacio-eustatic sea level on slope stability, and factors that co-vary with glacial cycles, such as the rate of sediment supply from rivers (Covault and Graham, 2010).
4.5.5. Should we date fewer landslides, but with greater precision? 877

This question is important because finite resources can be directed 878 towards obtaining a greater number of (lower precision) landslide 879 ages, or a small number of very well-dated examples. This study does 880 not provide a full statistical analysis of such a logistical trade-off. How- 881 ever, it is important that marginally increasing the number of poorly 882 dated landslides in global compilations, with uncertainties that are 883 well in excess of $\sim \pm 3 \mathrm{kyr}$, may not be a constructive way forward. 884 For instance, our work suggest that around 40 well-dated $( \pm 0.75 \mathrm{kyr}) 885$ landslides from a single setting would be necessary to allow robust sta- 886 tistical analysis of links between sea level and landslide frequency. Long 887 records from specific locations with multiple events are therefore the 888 most appropriate for isolating triggering mechanisms.

\section{Conclusions}

Previous work found that the most complete compilation of 41891 $\left(>\sim 1 \mathrm{~km}^{3}\right)$ submarine landslide ages in the last 30 ka suggests that 892 these hazardous events are temporally random (Urlaub et al., 2013). 893 However, it was unclear whether the landslides were temporally 894 
random, or whether the considerable uncertainties on most landslide ages made it impossible to tell. The primary conclusion of this study is that there are currently too few, sufficiently well-dated large landslides, to know whether these large submarine landslides are temporally random. The addition of realistic error bars to the ages of landslides that are non-random, can produce ages that appear temporally random.

Second, we show that it is likely that combination of landslide ages from different settings, each with different preconditioning and triggering factors that are offset in time, can easily produce a combined dataset that appears random in time. We show that just three distinct settings may be combined to produce apparently temporally random dates. This is important because most global databases of landslide ages probably include at least three distinct types of setting.

Third, we constrain the number of landslides, needed to test whether there is significant correlation between landslide frequency and global sea level. This was done simulating landslide ages that are correlated perfectly with sea level. The number of such landslide ages needed to test for a significant correlation with sea level ranged from 10 to 53 , with a mean of 38, even when landslide ages were known perfectly.

Finally, we provide some suggestions for the best future strategy for assessing the submarine landslide hazard. We suggest focussing on specific environment settings, and on a smaller number of well-dated landslides ( 40) to test for links with sea level.

The results of this study indicate the issues inherent with using the global record of submarine landslide occurrence in its current form. Our results indicate that both realistic age uncertainties and combination of data from multiple settings may make it hard to test for links between sea level and landslide frequency. However, it may be easier to test links between landslide frequency and more episodic and shorter duration events, such as the $8.2 \mathrm{kyr}$ climate event or meltwater pulse 1 , which have more distinctive time-series than sea level. Finally, the best means to understand links between sea level and landslide frequency may come from local studies with more numerous recurrence intervals (e.g. Clare et al., 2014, 2015), perhaps in conjunction with detailed records of localised environmental change.

\section{Uncited reference}

\section{Carter et al., 2012}

\section{Acknowledgements}

We would like to thank three anonymous reviewers. Their comments and suggestions greatly improved the manuscript. E. Pope was supported by the NERC Arctic Research Programme under project on whether climate change increases the landslide-tsunami risk to the $\mathrm{UK}(\mathrm{NE} / \mathrm{K} 00008 \mathrm{X} / 1)$. This research was completed as part of the EU FP7-funded ASTARTE (Assessment, Strategy and Risk Reduction for Tsunamis in Europe) Project.

\section{References}

Aspinall, W.P., Woo, G., Voight, B., Baxter, P.J., 2003. Evidence-based volcanology: application to eruption crises. J. Volcanol. Geotherm. Res. 128, 273-285

Baxter, P.J., Aspinall, W.P., Neri, A., Zuccaro, G., Spence, R.J.S., Cioni, R., Woo, G., 2008. Emergency planning and mitigation at Vesuvius: a new evidence-based approach. J. Volcanol. Geotherm. Res. 178, 454-473.

Beget, J.E., Addison, J.A., 2007. Methane gas release from the Storegga submarine landslide linked to early-Holocene climate change: a speculative hypothesis. The Holocene 17, 291-295.

Boe, R., Prosch-Danielsen, L., Lepland, A., Harbitz, C.B., Gauer, P., Lovholt, F., Hogestol, M., 2007. An early Holocene submarine slide in Boknafjorden and the effect of a slidetriggered tsunami on Stone Age settlements at Rennesoy, SW Norway. Mar. Geol. $243,157-168$

Bondevik, S. Stormo, S.K., Skjerdal, G. 2012. Green mosses date the Storegga tsunami to the chilliest decades of the $8.2 \mathrm{ka}$ cold event. Quat. Sci. Rev. 45, 1-6.

Bourget, J., Zaragosi, S., Ellouz-Zimmermann, N., Mouchot, N., Garlan, T., Schneider, J.L., Lanfumey, V., Lallemant, S., 2011. Turbidite system architecture and sedimentary processes along topographically complex slopes: the Makran convergent margin. Sedimentology 58, 376-406.
Brothers, D.S., Luttrell, K.M. Chaytor, J.D., 2013. Sea-level-induced seismicity and subma- 959 rine landslide occurrence. Geology 41, 979-982.

Bruschi, R., Bughi, S., Spinazzè, M., Torselletti, E., Vitali, L., 2006. Impact of debris flows and 961 turbidily currents on seafloor structures. Norsk Geologisk Tidsskrift 86, 317.

Carter, L., Burnett, D. Drew, S., Hagadorn, L., Marle, G., Bertlett-McNeil, D. Irvine, N.. 2009. 963 Submarine Cables and the Oceans - Connecting the World: UNEP-WCMC Biodiversi- 964 ty Series 31ICPC/UNEP/UNEP-WCMC, p. 64.

Carter L Milliman, JD. Talling PJ, Gavey, R. Wynn, R.B. 2012. Near-synchronous and 966 delayed initiation of long run-out submarine sediment flows from a record- 967 breaking river flood, offshore Taiwan. Geophys. Res. Lett. 39.

Clare, M.A., Talling, P.J., Challenor, P., Malgesini, G., Hunt, J.E., 2014. Distal turbidites reveal 969 a common distribution for large $(>0.1 \mathrm{~km} 3)$ submarine landslide recurrence. Geology 970 $42,263-266$

Clare, M.A., Talling, P.J., Hunt, J.E., 2015. Implications of reduced turbidity current and 972 landslide activity for the Initial Eocene Thermal Maximum-evidence from two distal, 973 deep-water sites. Earth Planet. Sci. Lett. 420, 102-115. 974

Clarke, S., Hubble, T., Airey, D., Yu, P., Boyd, R., Keene, J., Exon, N., Gardner, J., 2012. Subma- 975 rine Landslides on the Upper Southeast Australian Passive Continental 976 Margin-preliminary Findings, Submarine Mass Movements and Their Consequences. 977 Springer, pp. 55-66.

Covault, J.A., Graham, S.A., 2010. Submarine fans at all sea-level stands: tectono- 979 morphologic and climatic controls on terrigenous sediment delivery to the deep 980 sea. Geology 38, 939-942.

Daub, E.G., Ben-Naim, E., Guyer, R.A., Johnson, P.A., 2012. Are megaquakes clustered? 982 Geophys. Res. Lett. 39.

Dawson, A Bondevik, S. Teller, J 2011. Relative timing of the Storegga submarine slide, methane release, and climate change during the $8.2 \mathrm{ka}$ cold event. The Holocene 21, 985 $1167-1171$.

Dowdeswell, J.A, Kenyon, N.H. Elverhøi, A, Laberg J S., Hollender, FJ. Mienert J. Siegert, 987 M.J., 1996. Large-scale sedimentation on the glacier-influenced polar North Atlantic 988 Margins: long-range side-scan sonar evidence. Geophys. Res. Lett. 23, 3535-3538. 989

Garziglia, S., Migeon, S., Ducassou, E., Loncke, L., Mascle, J., 2008. Mass-transport deposits 990 on the Rosetta province (NW Nile deep-sea turbidite system. Egyptian margin): char- 991 acteristics, distribution, and potential causal processes. Mar. Geol. 250, 180-198. 992

Geist, E.L, Parsons, T., 2009. Assessment of source probabilities for potential tsunamis af- 993 fecting the US Atlantic coast. Mar. Geol. 264, 98-108.

Geist, E.L., Chaytor, J.D., Parsons, T., ten Brink, U., 2013. Estimation of submarine mass fail- 995 ure probability from a sequence of deposits with age dates. Geosphere 9, 287-298. 996

Goldacre, B., 2010. Bad Science: Quacks, Hacks, and Big Pharma Flacks. McClelland \& 997 Stewart 2010. Bad Scice: Quacks Haks, and Big Pha 998

Goldfinger, C., 2011. Submarine paleoseismology based on turbidite records. Ann. Rev. 999 Mar. Sci. 3 (3), 35-66.

Gracia, E, Vizcaino, A., Escutia, C., Asioli, A., Rodes, A., Pallas, R., Garcia-Orellana, J., 1001 Lebreiro, S.M., Goldfinger, C., 2010. Holocene earthquake record offshore Portugal 1002 (SW Iberia): testing turbidite paleoseismology in a slow-convergence margin. Quat. 1003 Sci. Rev. 29, 1156-1172.

Haflidason, H. Lien, R Sejrup, H.P., Forsberg C.F. Bryn, P. 2005. The dating and mor- 1005 phometry of the Storegga Slide. Mar. Pet. Geol. 22, 123-136. 1006

Hampton, M.A., Lee, H.J., Locat, J., 1996. Submarine landslides. Rev. Geophys. 34, 33-59. 1007

Hornbach, M.J., Lavier, L.L., Ruppel, C.D., 2007. Triggering mechanism and tsunamogenic 1008 potential of the Cape Fear Slide complex, US Atlantic margin. Geochem. Geophys. 1009 Geosyst. 8.

Hsu, S.K., Kuo, J., Lo, C.L., Tsai, C.H., Doo, W.B., Ku, C.Y., Sibuet, J.C., 2008. Turbidity currents, 1011 submarine landslides and the 2006 Pingtung earthquake off SW Taiwan. Terr. Atmos. 1012 Ocean. Sci. 19, 767-772.

Hühnerbach, V., Masson, D.G., 2004. Landslides in the North Atlantic and its adjacent 1014 seas: an analysis of their morphology, setting and behaviour. Mar. Geol. 213, 1015 343-362. 1016

Hunt, J.E., Wynn, R.B., Talling, P.J., Masson, D.G., 2013. Frequency and timing of landslide- 1017 triggered turbidity currents within the Agadir Basin, offshore NW Africa: are there as- 1018 sociations with climate change, sea level change and slope sedimentation rates? Mar. 1019 Geol. 346, 274-291.

Kendall, M., Stuart, A., Ord, J., Arnold, S., 1999. Vol. 2A: Classical Inference and the Linear 102 Model. Arnold [etc.], London [etc.].

Kennett, J.P., Cannariato, K.G., Hendy, I.L., Behl, R.J., 2000. Carbon isotopic evidence for 1023 methane hydrate instability during quaternary interstadials. Science 288, 128-133. 1024

Korup, O., 2012. Earth's portfolio of extreme sediment transport events. Earth Sci. Rev. 1025 $112,115-125$.

Laberg, J.S., Vorren, T.O., Dowdeswell, J.A., Kenyon, N.H., Taylor, J., 2000. The Andoya Slide 1027 and the Andoya Canyon, north-eastern Norwegian-Greenland Sea. Mar. Geol. 162, 1028 259-275.

Laberg, J.S., Vorren, T.O., Mienert, J., Haflidason, H., Bryn, P., Lien, R., 2003. Preconditions 1030 leading to the Holocene Trænadjupet Slide offshore Norway. In: Locat, J., Mienert, J., 1031 Boisvert, L. (Eds.), Submarine Mass Movements and Their Consequences. Springer, 1032 Netherlands, pp. 247-254.

Lambeck, K., Smither, C., Johnston, P., 1998. Sea-level change, glacial rebound and mantle 1034 viscosity fornorthern Europe. Geophys. J. Int. 134, 102-144. 1035

Lastras, G., Canals, M., Urgeles, R., De Batist, M., Calafat, A., Casamor, J., 2004. Characterisa- 1036 tion of the recent BIG'95 debris flow deposit on the Ebro margin, Western Mediterra- 1037 nean Sea, after a variety of seismic reflection data. Mar. Geol. 213, 235-255. 1038

Lebreiro, S.M., Voelker, A.H.L., Vizcaino, A., Abrantes, F.G., Alt-Epping, U., Jung, S., 1039 Thouveny, N., Gracia, E., 2009. Sediment instability on the Portuguese continental 1040 margin under abrupt glacial climate changes (last 60 kyr). Quat. Sci. Rev. 28, 1041 3211-3223. 1042

Lee, H.J., 2009. Timing of occurrence of large submarine landslides on the Atlantic Ocean 1043 margin. Mar. Geol. 264, 53-64. 
Leynaud, D., Mienert, J., Vanneste, M., 2009. Submarine mass movements on glaciated and non-glaciated European continental margins: a review of triggering mechanisms and preconditions to failure. Mar. Pet. Geol. 26, 618-632.

L'Heureux, J.S., Vanneste, M., Rise, L., Brendryen, J., Forsberg, C.F., Nadim, F., Longva, O., Chand, S., Kvalstad, T.J., Haflidason, H., 2013. Stability, mobility and failure mechanism for landslides at the upper continental slope off Vesterålen, Norway. Mar. Geol. 346, 192-207.

lopart, J., Urgeles, R., Camerlenghi, A., Lucchi, R.G., Mol, B., Rebesco, M., Pedrosa, M.T., 2014. Slope instability of glaciated continental margins: constraints from permeability-compressibility tests and hydrogeological modeling off Storfjorden, NW Barents Sea. In: Krastel, S., Behrmann, J.-H., Völker, D., Stipp, M., Berndt, C., Urgeles, R., Chaytor, J., Huhn, K., Strasser, M., Harbitz, C.B. (Eds.) Submarine Mass Movements and Their Consequences. Springer International Publishing, pp. 95-104.

Maslin, M., Mikkelsen, N., Vilela, C., Haq, B., 1998. Sea-level- and gas-hydrate-controlled catastrophic sediment failures of the Amazon Fan. Geology 26, 1107-1110.

Maslin, M., Owen, M., Day, S., Long, D., 2004. Linking continental-slope failures and climate change: testing the clathrate gun hypothesis. Geology 32, 53-56.

Maslin, M., Vilela, C., Mikkelsen, N., Grootes, P., 2005. Causes of catastrophic sediment failures of the Amazon Fan. Quat. Sci. Rev. 24, 2180-2193.

Masson, D.G., Harbitz, C.B., Wynn, R.B., Pedersen, G., Lovholt, F., 2006. Submarine landslides: processes, triggers and hazard prediction. Philos. Trans. R. Soc. A Math. Phys. Eng. Sci. 364, 2009-2039.

Masson, D.G., Arzola, R.G., Wynn, R.B., Hunt, J.E., Weaver, P.P.E., 2011. Seismic triggering of landslides and turbidity currents offshore Portugal. Geochem. Geophys. Geosyst. 12.

McAdoo, B.G., Watts, P., 2004. Tsunami hazard from submarine landslides on the Oregon continental slope. Mar. Geol. 203, 235-245.

Murray-Wallace, C.V., 2002. Pleistocene coastal stratigraphy, sea-level highstands and neotectonism of the southern Australian passive continental margin-a review. J. Quat. Sci. 17, 469-489.

Owen, M., Day, S., Maslin, M., 2007. Late Pleistocene submarine mass movements: occurrence and causes. Quat. Sci. Rev. 26, 958-978.

Parker, E.J., Traverso, C.M., Giudice, T.D., Evans, T., Moore, R., 2009. Geohazard Risk Assessment - Vulnerability of Subsea Structures to Geohazards - Risk Implications.

Paull, C.K., Buelow, W.J., Ussler, W., Borowski, W.S., 1996. Increased continental-margin slumping frequency during sea-level lowstands above gas hydrate-bearing sediments. Geology 24, 143-146.

Paull, C.K., Ussler, W., Holbrook, W.S., 2007. Assessing methane release from the colossal Storegga submarine landslide. Geophys. Res. Lett. 34

Pecher, I.A., Henrys, S.A., Ellis, S., Chiswell, S.M., Kukowski, N., 2005. Erosion of the seafloor at the top of the gas hydrate stability zone on the Hikurangi Margin, New Zealand. Geophys. Res. Lett. 32.

Piper, D.J.W., Cochonat, P., Morrison, M.L., 1999. The sequence of events around the epicentre of the 1929 Grand Banks earthquake: initiation of debris flows and turbidity current inferred from sidescan sonar. Sedimentology 46, 79-97.

Ramsey, C.B., 1998. Probability and dating. Radiocarbon 40, 461-474.

Reeder, M.S., Rothwell, R.G., Stow, D.A.V., 2000. Influence of sea level and basin physiography on emplacement of the late Pleistocene Herodotus Basin Megaturbidite, SE Mediterranean Sea. Mar. Pet. Geol. 17, 199-218.

Reeder, M.S., Stow, D.A.V., Rothwell, R.G., 2002. Late Quaternary turbidite input into the east Mediterranean basin: new radiocarbon constraints on climate and sea-level control. Geol. Soc. Lond. Spec. Publ. 191, 267-278.
Rothwell, R.G., Thomson, J., Kähler, G., 1998. Low-sea-level emplacement of a very large 1097 Late Pleistocene 'megaturbidite' in the western Mediterranean Sea. Nature 392, 1098 377-380.

Rothwell, R.G., Hoogakker, B., Thomson, J., Croudace, I.W., Frenz, M., 2006. Turbidite em- 1100 placement on the southern Balearic Abyssal Plain (western Mediterranean Sea) dur- 1101 ing Marine Isotope Stages 1-3: an application of ITRAX XRF scanning of sediment 1102 cores to lithostratigraphic analysis. Geol. Soc. Lond. Spec. Publ. 267, 79-98. 1103

Ruffman, A., 2001. Potential for large-scale submarine slope failure and tsunami genera- $\mathbf{0 1 1}$ tion along the US mid-Atlantic coast: Comment. Geology 29, 967-967. 1105

Sackett, D.L., Rosenberg, W., Gray, J.A., Haynes, R.B., Richardson, W.S., 1996. Evidence 1106 based medicine: what it is and what it isn't. BMJ 312, 71-72. 1107

Smith, D.E. Harrison, S Jordan, J.T., 2013. Sea level rise and submarine mass failures on 1108 open continental margins. Quat. Sci. Rev. 82, 93-103. 1109

Sornette, D., 2009. Dragon-kings, black swans and the prediction of crises. arXiv, preprint 1110 arXiv:0907.4290. 1111

Stigall, J., Dugan, B., 2010. Overpressure and earthquake initiated slope failure in the Ursa 1112 region, northern Gulf of Mexico. J. Geophys. Res. Solid Earth 115.

Sumner, E.J., Siti, M.I., McNeill, L.C., Talling, P.J., Henstock, T.J., Wynn, R.B., Djajadihardja, 1114 Y.S., Permana, H., 2013. Can turbidites be used to reconstruct a paleoearthquake re- 1115 cord for the central Sumatran margin? Geology 41, 763-766. 1116

Swan, A.R.H., Sandilands, M., 1995. Introduction to Geological Data Analysis. Blackwell 1117 Science, Oxford; Cambridge, Mass, USA.

Talling, P.J., Wynn, R.B., Masson, D.G., Frenz, M., Cronin, B.T., Schiebel, R., Akhmetzhanov, 1119 A.M., Dallmeier-Tiessen, S., Benetti, S., Weaver, P.P.E., Georgiopoulou, A., Zuhlsdorff, 1120 C., Amy, L.A., 2007. Onset of submarine debris flow deposition far from original 1121 giant landslide. Nature 450, 541-544.

1122

Talling, P.J., Masson, D.G., Sumner, E.J., Malgesini, G., 2012. Subaqueous sediment density 1123 flows: depositional processes and deposit types. Sedimentology 59, 1937-2003. 1124

Talling, P.J., Clare, M.A., Urlaub, M., Pope, E., Hunt, J.E., Watt, S.F.L., 2014. Large submarine 1125 landslides on continental slopes. Oceanography 27, 32. 1126

Tappin, D.R., Watts, P., McMurtry, G.M., Lafoy, Y., Matsumoto, T., 2001. The Sissano, Papua 1127 New Guinea tsunami of July 1998 - offshore evidence on the source mechanism. 1128 Mar. Geol. 175, 1-23.

1129

Urlaub, M., Zervos, A., Talling, P.J., Masson, D.G., Clayton, C.I., 2012. How do $\sim 2^{\circ}$ slopes fail 1130 in areas of slow sedimentation? A sensitivity study on the influence of accumulation 1131 rate and permeability on submarine slope stability. In: Yamada, Y., Kawamura, K., 1132 Ikehara, K., Ogawa, Y., Urgeles, R., Mosher, D., Chaytor, J., Strasser, M. (Eds.), Subma- 1133 rine Mass Movements and Their Consequences. Springer, Netherlands, pp. 277-287. 1134

Urlaub, M., Talling, P.J., Masson, D.G., 2013. Timing and frequency of large submarine 1135 landslides: implications for understanding triggers and future geohazard. Quat. Sci. 1136 Rev. 72, 63-82.

van Rooij, M.J.W., Nash, B.A., Rajaraman, S., Holden, J.G., 2013. A fractal approach to dy- 1138 namic inference and distribution analysis. Front. Physiol. $4 . \quad 1139$

Vanneste, M., Mienert, J., Bünz, S., 2006. The Hinlopen Slide: a giant, submarine slope failure 1140 on the northern Svalbard margin, Arctic Ocean. Earth Planet. Sci. Lett. 245, 373-388. 1141

Völker, D., Scholz, F., Geersen, J., 2011. Analysis of submarine landsliding in the rupture 1142 area of the 27 February 2010 Maule earthquake, Central Chile. Mar. Geol. 288, 79-89. 1143

Waelbroeck, C., Labeyrie, L., Michel, E., Duplessy, J.C., McManus, J.F., Lambeck, K., Balbon, 1144 E., Labracherie, M., 2002. Sea-level and deep water temperature changes derived 1145 from benthic foraminifera isotopic records. Quat. Sci. Rev. 21, 295-305.

Weaver, P.P.E., Kuijpers, A., 1983. Climatic control of turbidite deposition on the Madeira Abyssal Plain. Nature 306, 360-363. 